\title{
Perceptions of adult learners' readiness in Ghana for online instructions in higher education
}

\author{
Daniel Tetteh-Richter
}

Follow this and additional works at: https://researchrepository.wvu.edu/etd

\section{Recommended Citation}

Tetteh-Richter, Daniel, "Perceptions of adult learners' readiness in Ghana for online instructions in higher education" (2015). Graduate Theses, Dissertations, and Problem Reports. 6786.

https://researchrepository.wvu.edu/etd/6786

This Dissertation is protected by copyright and/or related rights. It has been brought to you by the The Research Repository @ WVU with permission from the rights-holder(s). You are free to use this Dissertation in any way that is permitted by the copyright and related rights legislation that applies to your use. For other uses you must obtain permission from the rights-holder(s) directly, unless additional rights are indicated by a Creative Commons license in the record and/ or on the work itself. This Dissertation has been accepted for inclusion in WVU Graduate Theses, Dissertations, and Problem Reports collection by an authorized administrator of The Research Repository @ WVU.

For more information, please contact researchrepository@mail.wvu.edu. 
Perceptions of adult learners' readiness in Ghana for online instructions in higher education

\author{
Daniel Tetteh-Richter
}

\author{
Dissertation submitted \\ to the College of Education and Human Services \\ at West Virginia University \\ in partial fulfillment of the requirements for the degree of \\ Doctor of Education in \\ Instructional Design and Technology
}

Ugur Kale, Ph.D., Chair

Regan Curtis, Ph.D.

Terrence Ahern, Ph.D.

Patricia Haught, Ph.D.

Department of Instructional Design and Technology

Morgantown, West Virginia

2013

Keywords: Online learning, developing world, andragogy, distance education, Africa, Ghana, adult learners

Copyright 2015 Daniel Tetteh-Richter 


\begin{abstract}
Perceptions of adult learners’ readiness in Ghana for online instructions in higher education
\end{abstract}

\title{
Daniel Tetteh-Richter
}

Online learning has become an integral component of higher education in the 21st century. Harnessing this potential has resulted in an increase in enrollment without the corresponding wear and tear on main campus infrastructure. Many institutions of higher education have incorporated online learning into their programs while recognizing that online learners are more likely to be adult students. As such, adult learners must have basic online skills that make them ready for online learning. Also, online programs should be guided by andragogy - a unique approach to educating the adult learner. And the adult learner must want to stay in an online program. For this reason, this study evaluated the perceptions of adult learners' readiness, the extent to which instruction in Ghanaian universities employ andragogical principles online and, whether learners preferred online to traditional instruction. Findings from the study showed that only two variables (gender and educational background) were perceived to have had any significant influence on adult learners ‘readiness’ for online instruction. 


\section{Dedication}

I dedicate this work to Dr. Daniel Hursh, my former head of department who did not cease to encourage me on this journey. He took a personal interest in my progress and even in his malady, he would whisper, "I will be happier if you finish and move on into the world. A good dissertation is the one that is finished."

May you find eternal rest from this weary world until we meet again.

Dr Hursh, my mentor, my advocate, my friend. 


\section{Acknowledgement}

I would like to acknowledge the Department of Learning and Technology for the opportunity to have a holistic and fulfilling educational experience during my tenure as a student in the department.

My heartfelt gratitude to Dr Ugur Kale (Chair) I am very grateful to his tireless support and encouragement. I would not exchange my Chair for the world.

To my committee, Dr. Patricia Haught, Dr. Neal Shambaugh, Dr. Reagan Curtis, Dr. Terence Ahern, I am sincerely grateful for your time, support and valuable guidance throughout my entire dissertation. Had it not been for all your selfless sacrifices, I would not have made it thus far. To all my friends and family who help in various ways, I say "thank you.” Most of all, I am extremely grateful to my wife Dr. Christine Lokko for her selfless sacrifices. Not only was she my number one critique, she was also my guide every step of the way.

Finally, my appreciation goes to my three sons: Zephan, Johan and Nikae for giving me the inspiration space needed to stay on course. 


\section{Table of Contents}

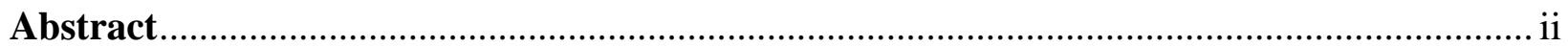

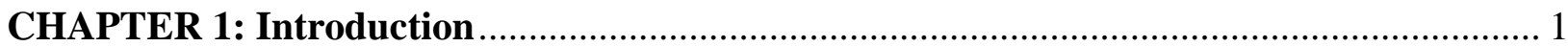

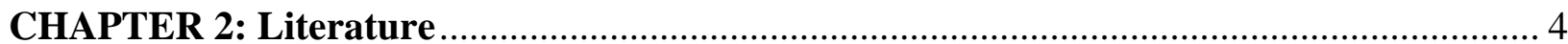

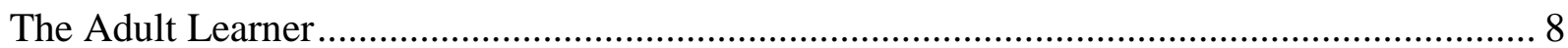

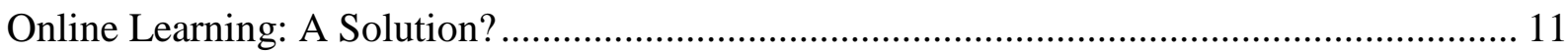

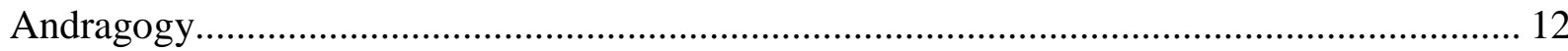

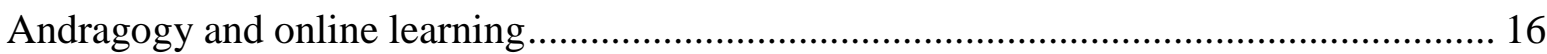

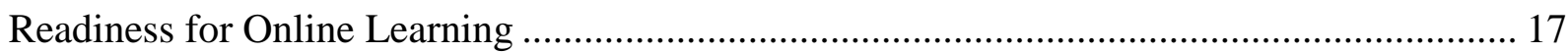

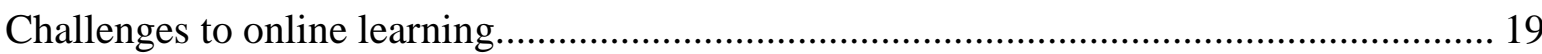

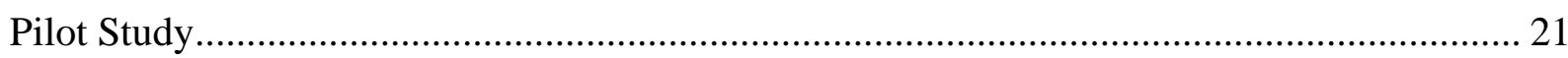

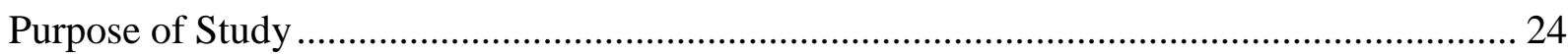

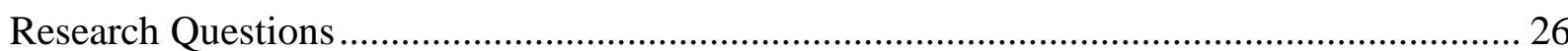

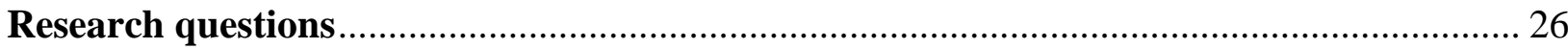

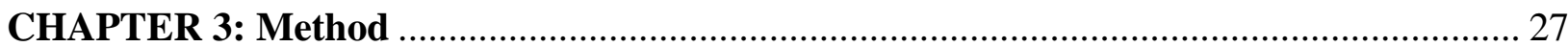

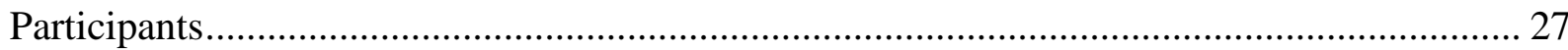

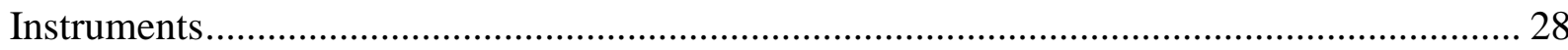

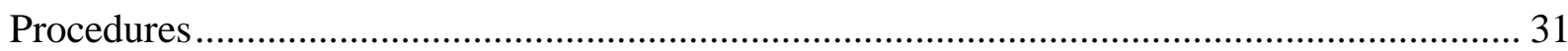

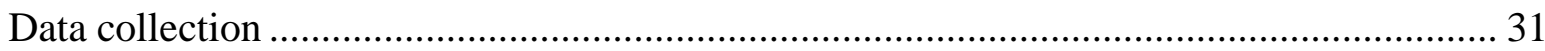

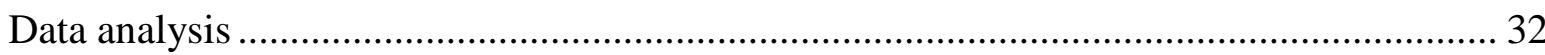

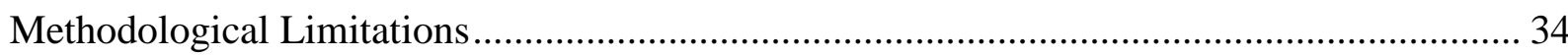

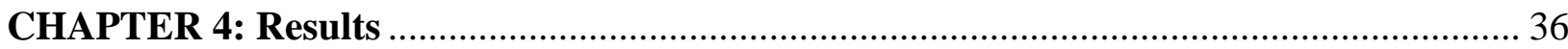

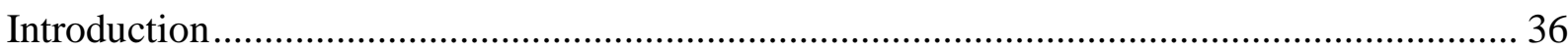

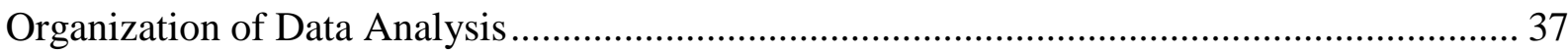

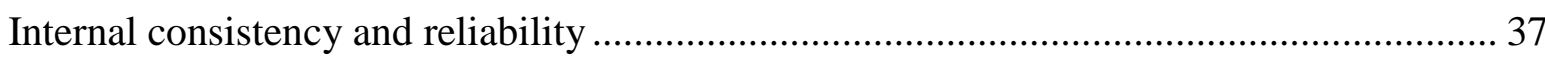

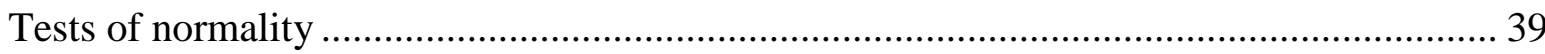

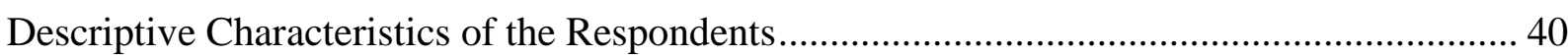

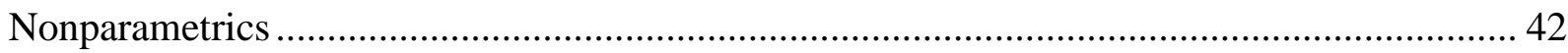

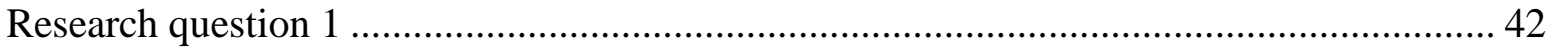

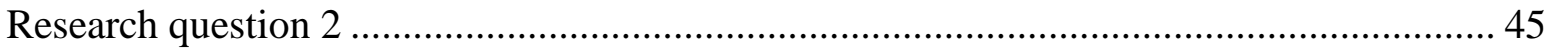

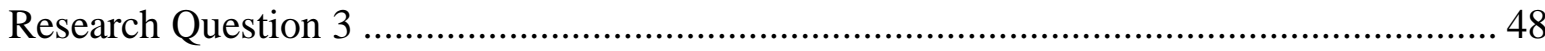

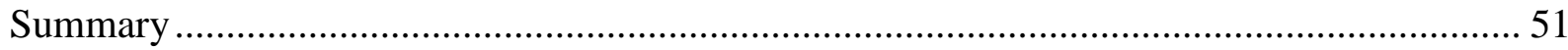

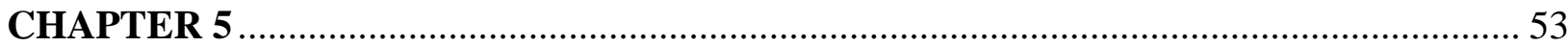

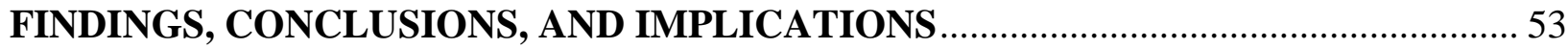

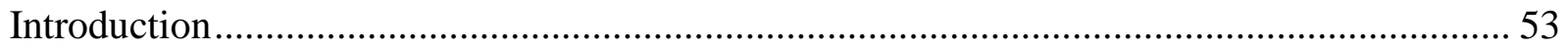




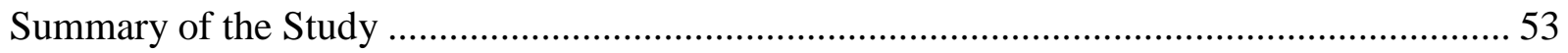

Descriptive Characteristics of the Respondents............................................................... 54

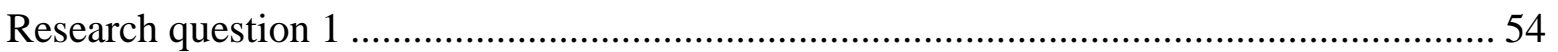

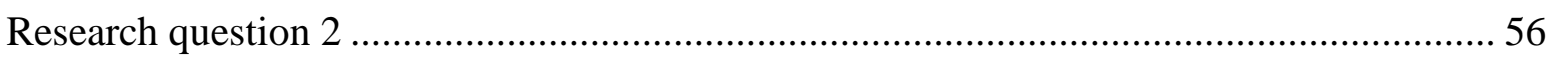

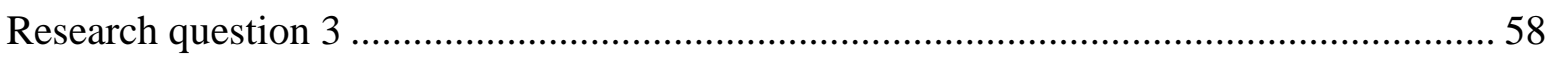

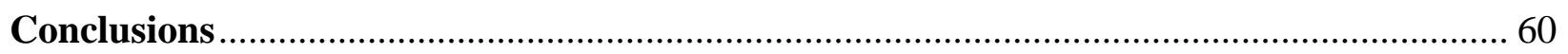

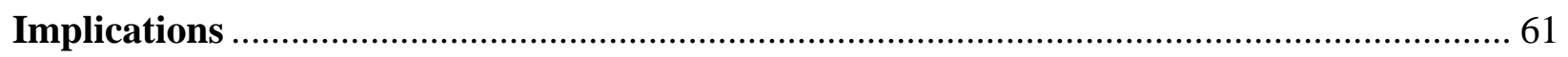

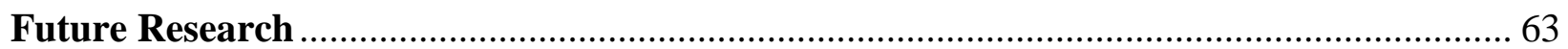

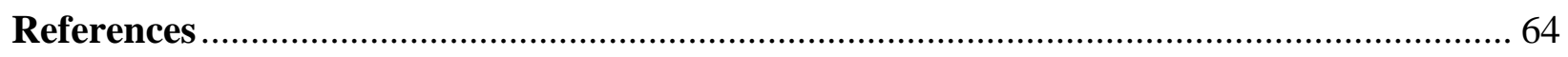

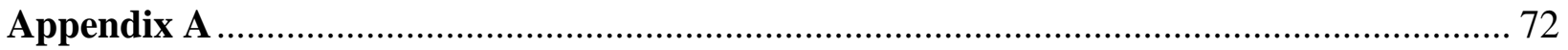




\section{List of Tables}

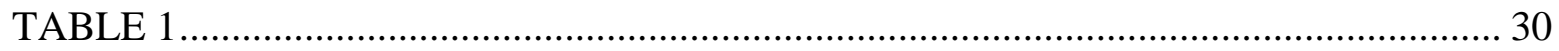

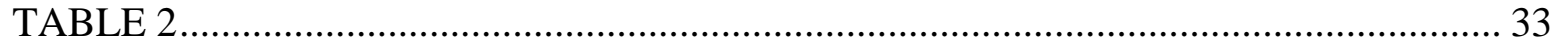

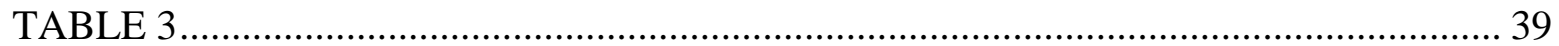

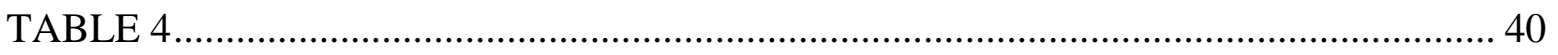

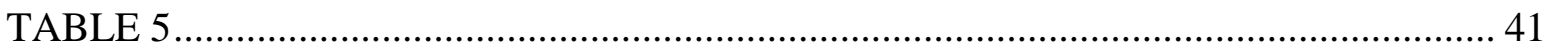

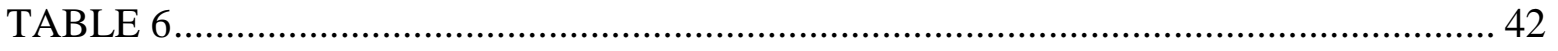

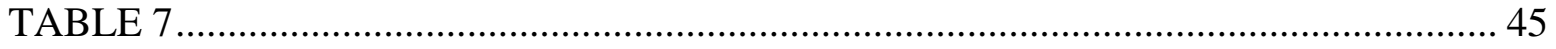

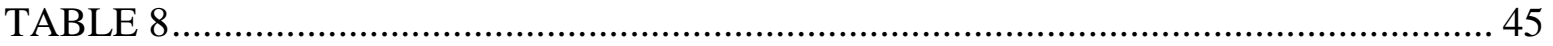

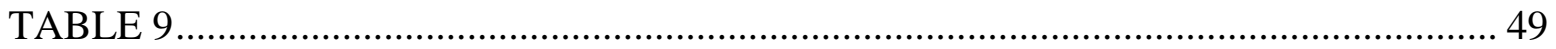

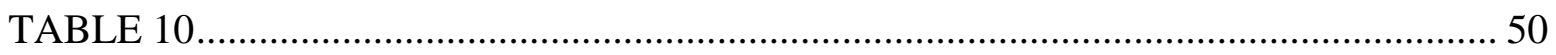




\section{List of Figures}

FIGURE 1:GHANA: ENROLLMENT IN UNIVERSITIES AND POLYTECHNICS.............. 6 


\section{CHAPTER 1: Introduction}

This study was motivated by the rapid technological advancements that this generation has experienced and continues to enjoy; particularly how these innovative practices can facilitate learning in the developing world. A decade ago, the concept of online education was not as widespread as it is today. One will be hard pressed to locate an institution of higher learning in the United States that has no online classroom. This medium offers learners and educators the opportunity to re-define the concepts of teaching and learning.

The developing world often trails the West in all aspects; however, the technological revolution has equally swept through Africa and Asia. Residents of the developing world join global conversations via social media. Those who are "left behind" are probably the villages that are not equipped with electricity and internet access. If a significant population of developing regions is connected to the rest of the world through internet, how can learning institutions channel this resource to benefit educators and learners?

At the end of this enterprise, this study hoped to be able to answer the following question: Are adult learners in Ghana ready for online instruction? Readiness is defined not just in the context of individual resources but, also as a state of the individual's mind. Do students have the technological skills and resources to succeed at online learning and, do online instructions incorporate adult learners' needs in the curriculum?

In Act Five Scene Two, Angus says of Macbeth, “....Now does he feel his title / Hang loose about him, like a giant's robe / Upon a dwarfish thief (Rauber, 1969).” Too often when ideas are copied and pasted from other countries without taking into consideration, the idiosyncrasies of receiving communities, one cannot but imagine the scenario of a giant robe on a dwarfish thief. For the 'giant robe' to fit comfortably on the dwarf, there may be the need to cut out parts of the robe or hem in the sides. Alterations are imperative! 
This study reviewed research that explored the viability of online education in Africa. It maintained that the online model is utilitarian and will be beneficial for a country like Ghana with so few universities. Public institutions are choked and faculties are overworked. In undergraduate classes, faculty student ratios average 1:1000. Lectures are held in large rooms where only the early birds have access to seats. Lecture halls lack audio visual equipment and microphones. The students who are not fortunate to sit at the back of the hall or stand outside on the corridors lose out on the lecture and are forced to rely on second hand notes. The majority of students in this scenario own smart/modern phones with internet and data processing capabilities with which they will update their friends on Facebook, Twitter, Instagram, and Whatsapp about the horrors of a college education. How can institutions harness the power of internet connectivity via such smart phones to facilitate instruction learning? Can institutions supplement the traditional brick and mortar classroom with an online model that will ensure that all students have access to lecture notes and can participate in the learning experience from the comfort of their dorms/homes thereby relieving the pressure off of the buildings?

This study identifies various ways in which potential students in Ghana are prevented from access to traditional education. This includes the handicapped students who have to contend with a campus set up that is not user-friendly, as well as the female population that is forced to choose familial obligations over the prospects of higher education. Could Ghanaian universities explore the benefits of online instruction as a way of expanding access?

The study reviewed research on how online models have been implemented in developed regions. It demonstrates that while some locales have had impressive results with this novel model, other areas were yet to report success. This study contends that for an online model to be successful in a developing country, specifically Ghana, certain factors must be present. They are 
a) a ready mindset (the possession of requisite technological skills) and access to technological resources; b) an instructional approach that incorporates the principles of andragogy, and c) the acceptance of the online model as a viable alternative to learning.

This study focused on potential consumers of online instruction, i.e. students. Any introductory class to business will stipulate that the potential business person must ensure that there is a need/market for the product being offered. In the absence of a market, it will be foolish for the business person to offer the service. Based on this logic, it is best to focus on potential consumers of online instruction. Once market research demonstrates that a demand exists for the product, subsequent research may focus on online instruction providers (faculty and institution).

In order to undertake this study, data was collected on adult learners in Ghana. Respondents were adults within adult learners' within the age range of 21 years to above 50 years living in Ghana. Surveys were administered online and respondents were invited to share their perceptions of their own readiness for online instruction and faculty teaching styles. They were also asked to answer questions related to their technological skill and resource levels as well as their perception of online instruction. Responses from the survey allowed the researcher to determine whether online instruction could be successfully implemented within university education in Ghana among adult learners.

This study is guided by the following questions:

1. What are the perceptions of Ghanaian adult learners on their level of readiness for online instruction?

2. What are adult learners' perceptions on the extent to which andragogy were incorporated by the faculty? 
3. To what degree do adult learners perceive online education as a viable alternative to traditional learning? 


\section{CHAPTER 2: Literature}

Many Ghanaians find themselves faced with making the decision of going back to school for a college degree, an advanced degree, or for a professional development course. This may be due to the fact that businesses have become more competitive, and many employers are limiting their employee pool to top-notch workers. To achieve this goal, employers are hiring candidates who have an advanced certificate beyond polytechnic diplomas (equal to a community college) or bachelor's degrees. A cursory examination of several Ghanaian job portals revealed that employers were scouting for candidates who had earned more than a first degree. A few decades ago, it was prestigious to hold a bachelor's certificate. However, the proliferation of private universities today has resulted in expansions in enrollment at both public universities and even the polytechnics. There are now more opportunities for Ghanaians to pursue bachelor's degrees than previously, holding a first degree is no longer considered exclusive (Boateng \& OforiSarpong, 2002). This puts even more pressure on adults who lack first degrees to return to school. It must also be noted that more students have the opportunity to attend universities today, unlike a few decades ago when students settled for polytechnics because they could not gain admission into four-year colleges.

Figure 1 below shows the increasing trend in public university enrollment as compared to the polytechnics over the last few years (Effah, Newman, \& Pillay, 2009). 


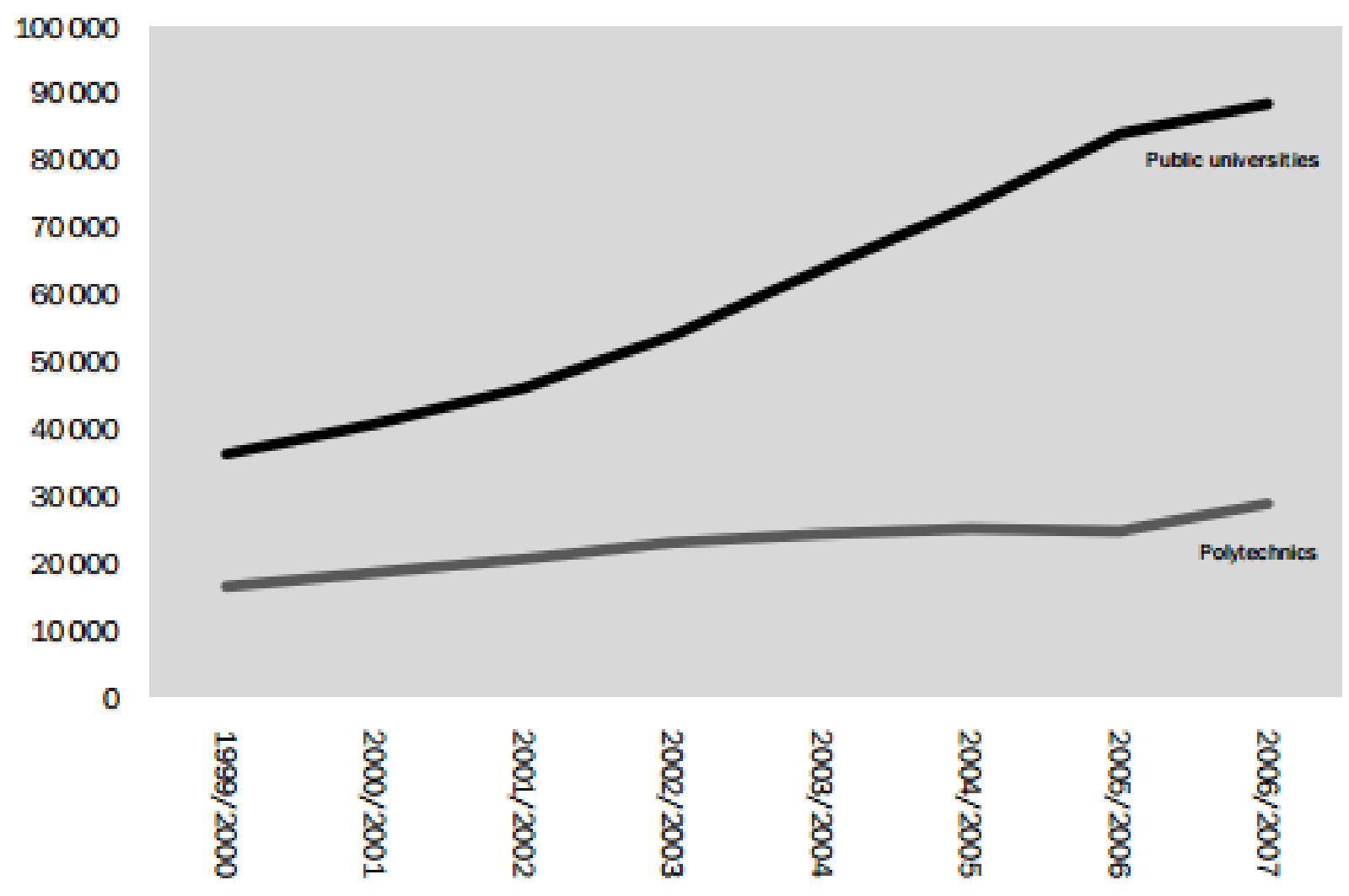

Figure 1:Ghana: Enrollment in Universities and Polytechnics

Source: Effah, Newman, \& Pillay, 2009

Over a period of 6 years (2001/2002 and 2007/2008) public universities have seen an increase of $103 \%$ in enrollment as compared to 69\% by the polytechnics (Effah, Newman, \& Pillay, 2009).

The United States Department of Labor's Employment and Training AdministrationETA (2007) reported that working adults with postsecondary degrees earned significantly more than their colleagues with just a high school education. According to the ETA, this difference in wages keeps widening, making college education more attractive. This phenomenon is reflective of the Ghanaian economy as well.

In the United States, a growing number of state and private owned universities have tried to milk their fair share of the influx of adult learners returning to school by moving most of their traditional courses online or creating completely new online courses. Allen and Seaman (2006) 
estimated that one-third of all higher education institutions make up about three-quarters of all online enrollments. These institutions look forward to adding new programs and growing existing ones. Eighty-three percent of the colleges and universities in the United States are expecting their online enrollments to increase over the coming year (Allen \& Seaman, 2006). A survey on more than 2,500 universities and colleges in the United States by Allen and Seaman (2010) for the Sloan Consortium noted that there was a 21 percent annual growth rate in online learning which far exceeded the 2 percent growth in brick and mortar institutions. In their more recent report, Allen and Seaman (2014) indicated that more than seven million students were taking at least one online course during the Fall 2012 semester. This represented an increase of four-hundred thousand plus students as compared to the previous year. What is more, this survey of more than 2,800 colleges and universities across the United States revealed that this proportion of online learners taking at least one course online is at an all-time high of 33.5 percent (Allen \& Seaman, 2014). The report also noted that the emerging trend Massive Open Online Courses (MOOCs) offered by certain universities and colleges across the country, has seen a slight increase of institutional use from 2.6 percent 5.0 percent in the last year. With the majority of institutions (53 percent) undecided on whether or not they will ever use MOOCs, there is the likelihood that more institutions will join the utility pool in years to come.

Clearly stakeholders in the United States have recognized the opportunities that online education offers in terms of access, convenience and for the institution, a good source of income generation. Hence, the adult learner can no longer be ignored when it comes to developing curriculum for online learning. 


\section{The Adult Learner}

Zamanou (1993) suggested seven reasons for why adult learners return to school: 1 . the need for academic credentials for career advancement, 2. for a career change, 3. life transitions, 4. currently unemployed and need for future employment opportunity, 5. for education sake, 6. required for current employment, and 7. for expanding social activities. Mbilinyi (2006) also identified a variety of motivational factors that push adult learners back to the classroom. Among these are: a sense of accomplishment, the opportunity to pursue long held goals, potential for increased income, the prospect for career change, and the ability to serve as positive role models for their children. The Allen and Seaman (2010) report, as well as the Bureau of Labor Statistics (2011a), noted that college enrollments in the United States increased significantly during the early years of the recession.

The preceding section offers an explanation for why adult learners return to school. These reasons are applicable to the Ghanaian context where the pursuit for advanced degrees is gradually becoming the norm, especially for employees in competitive career tracks. This has motivated many workers to re-enroll into school in order to earn a higher degree for the purposes of securing promotions and in some cases, in order to maintain their current positions.

In Ghana, the adult learners who enrolled in university programs (i.e the University of Ghana Business School) soon found that the institutions lacked faculty, infrastructure and the academic support that meets the unique needs of adult learners (Adei, 2006). The Lumina Foundation (2007) stated that 30 percent or more of college students today are made up of adult learners, and Ghana is no exception. This sizeable percentage of adult learners is the reason many colleges in the United States are showing interest in adult learners and increasing the number of courses that are structured based on the principles of andragogy (Tannehill, 2009). The National Center for Education Statistics NCES (2011) maintained that about 32.5 percent of 
the adult learners dropout before the end of their programs as compared to 19.2 percent of traditional students. This may be due to the lack of proper support services for the adult learners who face unique challenges in their quest for an educational degree. Jacot, Frenay and Cazan (2010) administered semi-structured interviews to 17 college dropouts and concluded that intrinsic motivation has a positive impact on perseverance and suggest that the presence of both intrinsic and extrinsic motivation might result in the retention of adult learners.

This lack of support services and infrastructure for the Ghanaian adult learner is even more pronounced. A growing positive trend is that most universities offer evening and weekend programs to accommodate the working clientele (Ababio, Omane-Adjepong, Boateng, Aidoo, Pharikhan, Rashid, Munyakazi \& Nsowah-Nuamah, 2012). Adult learners typically have to wear many hats in addition to being a student. Given that Ghana is a communitarian society, the adult learner does not only have to deal with responsibilities from the nuclear family alone, but also the extended family. Potential students who live in the cities have to contend with traffic congestion during the commute from work to school. It is to be expected that such a learner will not be performing optimally in class. In the United States, faculties strive to be accommodating to students. In Ghana, it is the other way round. Faculties are demi-gods who have to be worshipped. Kabuga (1977), stated that the adoption of pedagogy in developing countries, like Ghana, was "oppressive, silencing, and domesticating, among other ills.” He mentioned the fact that pedagogy alone made African education a "one-way traffic, glorifying the teacher whose wisdom could not be questioned.” Teachers benefited economically and socially by cramming educational content for profit. Yet, the African learner "starts with the unknown and ends with the unknown, (Kabuga, 1977)."An adult learner in this environment has to fight an uphill battle in the quest for a degree. This motivates adult learners to pursue college education outside the country. Common destinations are in American or British universities. 
On a positive note, Cretchley and Castle (2001) who evaluated the impact of andragogy on the beliefs and teaching philosophies of educators in South Africa noted that it provided an alternative to the autocratic learning environment by offering a democratic option that empowered learners. In a more recent study, Dhlamini (2012) explored the perceptions of adult learners, at a South African adult learning center, regarding the effectiveness of instruction methods in influencing retention. The author stated that instructors erroneously equated memorization with learning and lacked an understanding of the factors that motivate adult learners and, as such, were unable to retain students. Dhlamini (2012) noted that while instruction took place at the center, learning was absent and this was tied to the fact that pedagogy, rather than andragogy was the preferred means of instruction.

Rule and Modipa (2012) conducted a study on illiterate adult learners with disabilities who were enrolled in an adult literacy program in South Africa. They found that learners were motivated when there was a sense of belonging to a larger group and also that their voices mattered. A successful program for adult learners with disabilities must therefore aim to draw learners from dependency to activity, silence to dialogue, and from passivity to assertiveness. This advice is equally useful for any instructional environment with adult learners. Adult learners succeed when they are active participants in the educational process.

Kwapong (2007b) notes that one major problem plaguing university education in Ghana is the lack of access. There are seven main state-owned colleges in the country and about twentyfour private owned colleges (Adei, 2006). However, only 3.1 percent of Ghanaian high school graduates who qualify for university enrollment are absorbed in universities (Mangesi, 2007). Although the 3.1 percent is woefully low, there is the lack of infrastructure (i.e. lecture halls, library space, dorm rooms) to house all the applicants (Adei, 2006). Boissiere (2004) emphasized that governance structures in Ghanaian universities have not adapted to the enrollment influx and 
the demand on infrastructure; hence the basic infrastructure remains the same over the years. The United States National Center for Education Statistics (NCES, 2011) recorded that, of the 37 million US population that are within college-going age, 41 percent are enrolled in colleges and universities as of the year 2010. For a developed country like the US, this percentage is quite low. However the Ghanaian statistics tell a sadder story. This calls for a critical examination of alternative means to curb this overload on infrastructure and, one such alternative is online instruction.

\section{Online Learning: A Solution?}

The preceding section reviewed some of the challenges that adult learners face in the traditional classroom. Online learning offers convenience and flexibility for the adult learner. It provides the opportunity for working students to attend class from their work environment or from home. Students would not have to spend valuable time in traffic, commuting from the job to the classroom. Online learning also provides opportunities for physically disabled students who are typically excluded from the traditional institutions because of the lack of infrastructure that cater to their needs. In Ghana, Kwapong (2007a) saw online education as a blessing especially for female married students, who because of societal norms about the role of women are unable to patronize school programs that take place in the evenings. Such students might also be uncomfortable in study groups consisting primarily of male students that take place at night. Her evaluation of the current educational system for the adult learner is that it favors male students rather than their female counterparts. Kwapong (2007b) suggests that distance education would provide greater access to female students. Distance education as used in Ghana does not necessarily mean online education. It only means that students and teachers are not meeting on campus during regularly scheduled class hours. As Kwapong (2007a) further suggests, 
incorporating Information and Communications Technologies (ICT) into the distance education programs at the state universities would help provide more access to adult learners.

Education is directly correlated to a growing economy. An educated citizenry is a greater asset to any nation than an uneducated one. Governments that fail to educate their citizens would have to pay for educated citizens from other countries to perform functions that their citizens could have performed if they had the skills. It is imperative that governments invest in an educated population. In a developing country like Ghana where government and private business lack the finances to establish traditional educational institutions to accommodate the growing demand for college education, online education provides a viable and affordable alternative. That said, it is important to note while to reiterate that for online learning to sail smoothly, the principles of andragogy must be the vehicle that keeps it afloat. Thus, a look into andragogy was necessary in the context of this study.

\section{Andragogy}

Knowles, Holton, and Swanson (2005) referred to andragogy as the "art and science of teaching adults to learn". That is, the methods and techniques necessary for teaching adult learners effectively.

This current study was based on the assumption that adult learners will reap the most benefits from online learning. Knowles (1989), the proponent of the concept of Andragogy, believed that adults were significantly different from traditional students when it came to education and learning, as such learning programs for this group of students must consider or accommodate the adult learners' characteristics in order for learning to be effective and relevant (Knowles, Holton, \& Swanson, 2005).

The andragogical model is based on six assumptions: 


\section{Learner's Need to Know}

2. Self-Concept of the Learner

3. Prior Experience of the Learner

4. Readiness to Learn

5. Orientation to Learning

6. Motivation to Learn

The first assumption is, the learner's "need to know” which Knowles, Holton, \& Swanson (2005) employed to explain the adult learners' understanding of why it is necessary for them to learn what they are learning and whether they can place a value on what they learn.

The second assumption is that adult learners are independent and self-reliant (Knowles, 1989). This characteristic is distinct from the teenage years where the independent student is seen as the anomaly while other teens follow the winds of peer pressure. The adult learner on the other hand is self-directed, a trait that comes with maturity.

The third assumption is that adult learners have a wealth of experience to draw upon in the classroom. It also means that instruction must relate to previous experiences. Knowles (1989) maintains that the instructors must value these experiences. They need to know their students' history and incorporate that experience in their teaching.

The fourth assumption is that adult learners are encouraged to learn when the material is relevant to them. It means that a civil servant will excel in a public administration class whereas he or she might struggle in a general education geography class. Similarly, military personnel taking college classes will excel in political science courses, as classes in international relations and American government particularly relate to their current roles as service men and women. 
The fifth assumption is that adult learners learn best when material is problem centered or contextual (Knowles, Holton, and Swanson 2005). Adult learners often play several roles simultaneously (e.g., spouses, parents, caregivers, employees, students, etc.). Time is a precious and scarce commodity for this group of people. Fidishun (2000) noted that this group of people needs to focus on what is important to them. It is therefore imperative that the instructor make the course work relevant.

The sixth assumption of Knowles, Holton, and Swanson (2005) made is motivation to learn. "Adults are motivated to learn by internal factors rather than external ones" (Merriam \& Caffarella, 1999, p. 272). Activities that build self-esteem or provide a sense of accomplishment motivate adult learners. It is for this reason that most academic programs designed specifically for adult learners, are in modules, allowing students to see their goals being achieved, one step at a time. To help build self-esteem, instructors must be respectful to their learners (Fidishun, 2000).

Advocates of andragogy agree that teaching adult learners demand entirely different teaching methods and approaches than pedagogy (Kabuga, 1977; Knowles, 1989). Caffarella and Daffron (2013) surmised that scholars in the field of adult learning identify three content areas to demonstrate the connection between adult learning and instruction. They are experiential learning, transformational learning and non-Western ways of learning. The next section briefly reviews some of the research on experiential learning.

Knowles, Holton, and Swanson (2005) maintained that learners draw from their stages of life experiences to facilitate meaningful learning. This group of learners integrates novel concepts by linking them to pre-existing knowledge (Bergsteiner, Avery, \& Neumann, 2010; Gay 1994; Kasworm, 1997). Sealey-Ruiz (2007) echoed Gay’s (1994) conclusion that instructors should allow students to bring their cultural experiences and perspectives into the educational 
experience. Sealey-Ruiz (2007) conducted a qualitative study with 15 Black female students in a first year, second semester required English composition course. The researcher designed a culturally relevant curriculum that was influenced greatly by the students/respondents in the study. Respondents were allowed to "lead" and were granted the space to dialogue and share their experiences. Sealey-Ruiz (2007) concluded that culturally relevant curriculum allowed students to feel empowered and increased the potential for them to succeed.

Transformational learning takes place when adult learners encounter life changing events that re-define existing paradigms (English \& Peters, 2012; Mezirow, 1978; Newman, 2012) Caffarella and Daffron (2013) noted that not all adult learners may find a particular event transformational however critical reflection is an essential component of this learning process. According to Mezirow, Taylor, and Associates (2009), instructors must incorporate storytelling, creative and reflective writing, conversations and coaching to help adult learners as they proceed through the transformational phases of learning.

Caffarella and Dafron (2013) reviewed the literature on non-Western learning styles and posited that scholars in this field focus on the "communal nature of learning, the oneness of learners with their natural world, the oral tradition of learning, and knowledge as holistic and grounded in the experience of daily living and culture” (p. 59). The scholars recognized that adult learners differ in various ways and one’s ethnic background influences the learning process. Caffarella and Daffron (2013) suggested the inclusion of oral traditions such as storytelling, use of proverbs and metaphorical language in the instruction planning process.

In summary, scholars in the field of adult learning recognize that instruction must be designed in a way that the needs and varied learning styles of adult learners are incorporated. Educators can no longer design one-size-fits-all curricula without taking the characteristics of the adult learner into consideration. This exercise clearly requires more effort on the part of faculty. 


\section{Andragogy and online learning}

Knowles, Holton, and Swanson (2005), postulated that technology will contribute tremendously in shaping adult learning in the $21^{\text {st }}$ century. One of the ways in which technology

will help adult learners is by providing them with a rich learning experience in which the selfdirected learning style of the adult is surrounded with unlimited access to learning materials online. For example, an adult learner faced with a statistical problem can have access to programs and open source software that are available online like Excel, SPSS, ADaMSoft, Chronux, SOFA Statistics, etc. and other professional groups' resources. Thus, it offers adult learners alternative problem solving skills they can select from to apply to their current situations.

Online education has boomed exponentially in our generation. Advertisements abound on the internet and television, all aimed at luring nontraditional students back to the classroom. The online model has definite attractions; the fact that learners do not have to relocate and that learning can take place anywhere and everywhere. A personal conversation with an instructor in an online college in Missouri revealed that the number of truck drivers enrolled in online programs is rising steadily. Education has truly become mobile. Given the fact that online learning is very attractive to adult learners, it is a no brainer that instruction via this medium has to incorporate andragogical instructional principles to ensure that both teaching and learning take place. However, to guarantee success for the adult learner online, Ghanaian universities need to overcome those foreseeable and unforeseeable obstacles that trammel smooth sailing in the online environment. A good first step would be to evaluate student's readiness for online learning. The following section discusses the topic of readiness. 


\section{Readiness for Online Learning}

According to Lin and Hsieh (2001), students who succeed in the online environment are those that are self-directed and take responsibility for their learning. Watkins, Leigh and Triner (2004) argued that students who demonstrate success in the conventional classroom may not necessarily succeed in the online environment. They suggest that students need to take a readiness assessment to determine their suitability for this medium of learning. This advice is echoed by Hung, Chou, Chen and Own (2010)—-that distance educators have to set an evaluation system in place that allows potential learners to assess whether they are prepared to pursue an online education. In order to ascertain the viability of an online learning model in Ghana, it is expedient to measure adult learner’s perceptions of their readiness for online learning.

Several scholars have experimented with a variety of instruments to measure readiness for online learning. Mattice and Dixon (1999) created a survey to evaluate their student's interest and readiness for online education. The survey asked respondents about their previous experience with online education, access to technology and also their future plans to enroll in a distance education class. Their survey consisted of three indices: a) the readiness index (focused on topics such as time management, students' self-direction and preferences to feedback; b) the technology index (centered around student's experience and access to the Internet and email) and c) the interest index (general interest in online education).

McVay $(2000,2001)$ developed a survey to assess students' readiness for online learning. Her 13-item instrument concentrated on their comfort with the online environment as well as their learning habits. Smith, Murphy and Mahoney (2003) subjected McVay’s survey to a reliability analysis and a factor analysis by administering the instrument to 107 undergraduate university students in the United States and Australia. They authors concluded that it was a 
reliable and valid instrument for evaluating self-management of learning and comfort with elearning.

Bernard, Brauer, Abrami and Surkes (2004) expanded McVay's instrument to 38 items to allow for predicting student online learning achievement. Their survey focused on a) students' perceptions of the Internet as an effective tool for learning and b) student's faith in their ability to succeed in a distance education course.

Hung et al. (2010) set out to develop and validate a multidimensional instrument for college students' readiness for online learning. They collected data on 1051 students in Taiwan who were taking online courses. Using confirmatory factor analysis their Online Learning Readiness Scale (OLRS) was validated in five dimensions: self-directed learning, motivation for learning, computer/Internet self-efficacy, learner control and online communication self-efficacy. Findings from their study demonstrated that students' levels of readiness were high in computer/Internet self-efficacy, motivation for learning and online communication self-efficacy but were low in learner control and self-directed learning.

Kaymak and Horzum (2013) conducted a study online with 320 students post-graduate students in Turkish University to determine whether a relationship existed between readiness levels for online learning and the perceived structure and interaction in online learning environments. Using structural equation modeling, they found that readiness for online learning correlated positively with interactions in learning environments. In other words, an increase in readiness resulted in an increase in interaction in the learning environment. Readiness was gauged by computer/Internet self-efficacy, self-directed learning, student control, motivation and online communication self-efficacy. The authors concluded that in order for students to succeed in online education, self-directed learning and learner control attributes should be present. 
The preceding discussion has demonstrated that a successful online program must start with the evaluation of students' readiness for this platform. As a result, this paper included an instrument that assesses Ghanaian adult learner's readiness for online instruction. The Methodology section discusses this topic further. The next section reviews some of the challenges that an online program might face in Ghana.

\section{Challenges to online learning}

It is evident that online education does offer several advantages for university education in Ghana, particularly for the adult learner. However, there are many challenges associated with this new mode of learning. Adei (2006) acknowledged that while ICT integration will go a long way in easing the lack of facilities such as lecture halls, reading rooms, libraries, etc, it is worth noting that there is still a significant amount of funding that would be needed at the initial stage to create an environment conducive for online learning. Universities will have to invest in a broadband infrastructure, Wi-Fi, servers, technical staff, and faculty training to ensure a successful transition to online education.

In addition, Ghanaian university students, especially at the undergraduate level, frown on online education. This group of students prefers face-to-face interaction to distance learning. Asunka (2008) reported that majority of the respondents expressed deep animosity towards online learning specifically, asynchronous online learning. Students complained that, online learning was too complicated, time consuming and took a lot out of the student (Asunka, 2008). However, Asunka (2008) conjectured that students' lack of interest may be due to "illstructured" learning activities. Another issue is that Ghana has a high faculty-student ratio even in the traditional classroom settings. Adei (2006) stated that for the 2004/2005 academic year, 50 percent of undergraduates in University of Ghana Business School as well as two-thirds of 
Master's students only had one full-time faculty. Adei (2006) noted that the story is not very different for private colleges who had only two or three full-time faculty with Master's degrees in an entire department. This lack of faculty pool in the traditional classroom setting suggests that there will be a dearth of faculty who have the technological skills to enter into the world of online learning.

The low percentage of faculty implies a lack of support and services for tutoring, academic planning and scheduling, mentoring and technical support. The end repercussion of this is isolation from the learning process which goes a long way to complicate the learning process for adult learners (Galusha, n.d). Academic support for online adult learners is imperative for a successful program. Adult learners need tutoring, mentoring, and timely help (Galusha, n.d) in order to ensure a successful learning process.

As a third-world country, Ghana is plagued with a plethora of problems that pose serious challenges to an educational program that is heavily dependent on technology. There are frequent power outages and broadband usage is low. The situation is not completely hopeless though. The Ghana government highlighted the importance ICT will play in education in its Ghana Poverty Reduction Strategy Paper 2003-2015 and the Education Strategic Plan. The Ghana parliament also passed a bill in 2004 that suggested using ICT to facilitate educational development, under the Accelerated Development Policy - ICT4AD (Mangesi, 2007). Mobile modems are common and are quite affordable (Brown, 2005). Internet cafes are very common, and most business organizations have internet access for employees to use.

The conclusion is that, while Ghana faces more challenges to instituting online learning than its' Western counterparts, resources do exist (even if inadequate) for online education. The benefits to be gained from such a venture are immense and therefore worth exploring. Countries in the Western world have had more than a decade of experience with the online model that 
Ghana can emulate. de la Varre, Keane, and Irvin (2010) studied four hundred-rural schools in the United States with the goal of identifying barriers to distance learning in various districts. The authors found that, while 64 percent lacked funding for distance education, 53 percent thought distance education was not a priority. de la Varre, Keane, and Irvin (2010) also found that 45 percent of those rural schools had difficulty implementing distance learning, 47 percent of the schools' personnel lacked distance education training, 15 percent had no technologically enhanced classrooms, and 7 percent had insufficient internet/intranet connectivity. Though rural, such barriers in the United States are likely to be twice the blockade in Ghanaian urban areas.

That is not to say the digital divide is too wide for Ghana to bridge. As the Ghanaian proverb says "a child who needs to run must first learn how to walk.” Hence, Ghana must delineate its infant steps on the innovations of the rural areas in advanced countries like the United States. Ghana therefore has the advantage, as a late bloomer to learn from the mistakes and successes of those who have already ventured into this area.

In order to test the water to find out how deep the 'rabbit hole' was, the researcher conducted a pilot study to ascertain some of the points raised above.

\section{Pilot Study}

The purpose of the pilot study was to explore the perspectives, of Ghanaians living abroad, concerning Ghana’s readiness for distance education via online learning (Tetteh-Richter, 2014). The researcher interviewed Ghanaians living in a mid-Atlantic region. The criteria for selecting respondents was that they needed to have obtained (at least) their bachelor's degrees in Ghana prior to moving to the US for graduate studies. This was important because the cross cultural and educational experiences allowed for comparison of educational experiences in the two countries. 
The survey instrument was based on the following research questions:

What perceptions do Ghanaians from the mid-Atlantic University have of the following;

i. Why Ghanaian adult learners return to school?

ii. Integrating online learning in higher education in Ghana?

iii. What challenges will impede the integration of online learning in Ghana?

iv. What opportunities will the integration of online learning offer adult learners in Ghana?

v. What lessons Ghanaians drawn from integration of online learning in the midAtlantic University?

vi. Ghanaians experiences in higher education with regards to principles of andragogy?

The researcher used interviews as the data collection procedure. The interview instrument was based on the research questions and consisted of open-ended questions to allow participants to freely express themselves. Eight respondents participated in the interview. Given the academic and familial responsibilities of respondents, it was challenging to coordinate schedules. As a result the interviews and focus group discussion, for seven of the respondents, had to be scheduled at the same time. The seven participants were in a room with the interviewer who asked each participant a question at a time. Participants took turns responding to questions. At the end of the individual question session, participants engaged in a non-moderated discussion on the subject.

The study revealed that Ghanaians return to school for professional and private reasons. There were mixed results for the question of whether Ghana was ready to integrate online learning in colleges and universities. The conclusion was that the infrastructure needed to run a fully functional online program was lacking. A concern was also raised about the readiness of 
faculties' state of mind for such a program. It was noted that the preponderance of aged faculty in state universities made it less likely for them to welcome online models with open arms. The pilot study supported the assertion that university education in Ghana does not incorporate andragogical principles in curriculum development. Respondents noted that while institutions vary course offering times to make it accessible to working students, faculty do not design curriculum with the needs of adult learners in mind.

While there was the concern that some students may not be mentally ready, it was established that a significant number of Ghanaians utilize the internet for social networking and are therefore mentally prepared to integrate online education. It was also reported that some private and public institutions are already experimenting with online models.

The study identified several challenges to the successful integration of online education in Ghana, among which are the lack of stable electricity and internet, lack of technical expertise and the lack of capital to facilitate the integration of online learning. That said, the study recognized that online learning offers tremendous benefits to access, convenience and flexibility, which will be welcome by students who are struggling to juggle career and family responsibilities with an education. The elimination of physical infrastructure in the online system can result in lower tuition costs for students thereby making this an attractive medium of education.

Findings from the pilot study also demonstrated that Ghana can learn from other institutions that have experimented with this model. Ghanaian schools can incorporate occasional physical meeting times, as students raised in a communitarian system might not be very accepting of a model that allows for no physical interaction. This can be supplemented by chatrooms and video resources that imitate face-to-face interaction. Public universities can explore outside sources of funding so that government inaction does not prevent such institutions 
from joining the global technological revolution. To help mitigate the effects of constant power outages on learning, it was suggested that Ghanaian colleges begin their experimentation with online learning using an asynchronous model.

The study provided several possible solutions to the challenges affecting online learning in Ghana. The various solutions proposed offer a ray of hope as it demonstrates that while challenges exist, it is not impossible to conceive of online education in Ghana.

The pilot study provided useful lessons about the main study: first, the research questions were overly ambitious and needed to be streamlined; secondly, focusing on students' perceptions only will allow for a more accurate evaluation about students 'readiness for online learning and whether faculty employed andragogical principles. Finally, quantitative analysis will be a better gauge for sampling perceptions, resulting in the shift from interviews in pilot study to surveys in main study.

\section{Purpose of Study}

Given the issues raised in the literature review, a) the fact that adult learners are returning to the college classroom, b) the reality that universities in Ghana have limited infrastructural resources, and are therefore unable to effectively meet the demand for their services, and c) the fact that distance education will provide invaluable options to adult learners, among other factors, there is a need to determine whether online learning can be successfully implemented in university education in Ghana amongst adult learners.

As a first step to achieve this goal, the study focuses on the perceptions of adult learners in Ghana. This study was based on the assumption that certain key indicators need to be present in order for online learning to succeed. 
They are 1) infrastructure ready mindset, 2) instructional methods that incorporate the principles of andragogy and 3) students’ positive perceptions of the online environment. A viable online program will thrive in an environment where students have the requisite technological skills and resources (for example a personal computer and access to internet). Findings from the pilot study indicated that Ghana faces infrastructural challenges that might impede online learning. Among the challenges listed were frequent power outages, lack of access to computers, and lack of internet access. This study shifts focus from the institutions and infrastructural challenges and focuses on students. By knowing the skills and technological resources available to adult learners, this study can make certain conclusions about the viability of an online model.

Secondly this study suggested that for an online program to succeed, the instruction must be student-centered. The online model has an inherent weakness of distancing the instructor from the learner. In order for this medium of instruction to succeed, instructional designers and faculty have to keep the student at the center of the design process. This study maintains that instruction must take andragogical principles into consideration. Adopting this method places the student in the center of curriculum design and would be the most effective approach for adult learners. These groups of learners were more likely to have the resources to acquire the technology needed for this type of education. They are also the group of students who will benefit the most from this flexible medium and whose instruction demands the implementation of andragogy for successful implementation.

Findings from the pilot study suggested that andragogical principles were not used in instruction. While this conclusion supports findings in the literature, it was prudent to collect data from Ghanaian students about faculty's employment of andragogy in instruction. Students may not be knowledgeable about the technical term “andragogy” however faculty may be incorporating aspects of this principle in their teaching. Findings from the proposed study that 
reveal information about the extent to which Ghanaian faculty implement andragogy in their teaching, was instrumental in making educated guesses about the extent to which online education would succeed in Ghana.

Finally this study maintained that for an online program to thrive, consumers should have a positive evaluation of the model. If students do not think that online learning is comparable to the traditional method, in terms of quality, they may not opt for this medium even when presented with this option. If students are not well informed about the nature of online learning, they may be hesitant in exploring this option. Responses to questions on this subject did allow researcher to hypothesize about the viability of an online model in Ghana.

\section{Research Questions}

As the first step, this study aimed at examining the perceptions of Ghanaian adult learners about the viability of online education in Ghana. Particularly, the study focuses on adult learners' perception on (1) their technology access and skill levels, (2) extent to which andragogy is incorporated in online classes, and (3) to what degree (or whether) online education is as a viable alternative to traditional learning.

\section{Research questions}

The research questions are as follows:

1. What are the perceptions of Ghanaian adult learners on their readiness for online learning?

2. What are adult learners' perceptions on the extent to which andragogy is incorporated by the faculty?

3. To what degree do adult learners perceive online education as a viable alternative to traditional learning? 


\section{CHAPTER 3: Method}

The purpose of this study was to determine the perceptions of Ghanaian adult learners about the viability of online instruction in Ghana. This paper contended that a successful online program was one that offered student-centered instruction and targeted adult learners who had the technological skills for this mode of online instruction. In order to achieve this objective, surveys were administered to adult learners who were currently enrolled or prospective students in Ghana via social media and personal emails. The survey instrument focused on adult learners’ perceptions about their readiness for online instruction; their perceptions on whether faculties incorporate andragogy in teaching, and finally whether adult learners perceived online instruction as a viable alternative to traditional learning.

\section{Participants}

The questionnaire was administered to prospective adult learners living in the urban areas of Ghana, specifically, Accra, Tema and Kumasi. Respondents were mostly previous students who have had some type of post-secondary education. The United States Embassy in Accra, Ghana notes that over 300,000 Ghanaians within adult learners' age range are enrolled at the university level $(\mathrm{N}=300,000)$. According to web-based survey organization (CheckMarket website), at that population size, an ideal sample size was 1920 with an expected response of 384, and a margin of error of 5 percent at the 95 percent confidence level. A Convenient Sampling method was used to select respondents. A little over 1200 participants were contacted through social media, most of whom were on the researcher's social media listserv. Out of the 1200 participants contacted, only 513 participants took the survey. 


\section{Instruments}

The first section of the survey instrument posed demographic questions such as age, gender, work status, marriage status, and student status. Responses from this section allowed comparison among data to determine if variations exist in responses based on demographic data.

To answer the first research question which is: "What are the perceptions of Ghanaian adult learners on their readiness for online learning?” McVay’s (2000, 2001) survey which measures readiness for online learning was replicated. McVay $(2000,2001)$ designed a 13-item survey that focused on basic skills and aspects of online learning. Hung et al. (2010) argued that McVay’s surveys did not include measurement of technical computer-use skills and internet navigation skills. The authors incorporate questions that address these aspects of readiness. This paper uses McVay’s 13-item survey, with the exception of one question which asks respondents to compare online learning to traditional learning. Since this question was addressed in detail in another section of the questionnaire, the researcher eliminated it. McVay’s questions are employed together with questions from Hung et.al (2010) that focus on technical computer-use skills as well internet navigation skills.

The second research question, “what are students’ perceptions on the extent to which andragogy is incorporated by the faculty?” To answer this question a modified version of the Student Orientation Questionnaire (SOQ) created by Christian (1982) adapted to collect data on adult learners in Ghana. The (SOQ) is a tool that drew on Hadley’s Educational Orientation Questionnaire (EOQ) and is employed to measure student preferences for either andragogical or pedagogical instruction. Hadley (1975) developed the EOQ to measure the differences in perceptions among adult educators concerning effective learning procedures. Hadley (1975) believed that educators have both andragogical and pedagogical attitudes. On a numerical scale, respondents that earn high (positive) scores have an andragogical education orientation while 
those with lower (negative) scores had a pedagogical orientation. Educators that have an andragogical orientation employ more student centered methods and those that have pedagogical orientations use teacher centered methods

Christian (1982) drew his sample from a military educational environment. While Wilson (2005) sees this as a limitation, the SOQ is a relevant instrument for collecting data from respondents in an educational system where faculty are viewed as demi-gods and students are receptacles to be filled. The SOQ questionnaire is made up of 50 statements of which 25 are andragogical and 25 are pedagogical. The statements are randomly listed on the questionnaire and consist of a five-point Likert scale ranging from five representing almost always to one representing almost never.

The SOQ questionnaire was modified for this study. While Christian (1982) designed the SOQ to measure students preferences for andragogical versus pedagogical instructional styles, the goal of this study is to gauge students' perceptions on the extent to which andragogy is incorporated by the faculty. While Christian (1982) posed a question such as: "I feel the instructor should use group activities rather than such methods as lectures”, this study modified the question to a statement: "Instructor uses group activities rather than such methods as lectures” and invites respondents to agree or disagree with that statement. Another way in which the SOQ was modified was that the list of questions was reduced. The researcher felt that some of the questions in the SOQ were culturally sensitive and may be misinterpreted by respondents in Ghana. There were also questions that were not applicable to the needs of this study and were therefore eliminated.

To answer the third research question which is "To what degree do adult learners perceive online learning as a viable alternative to traditional learning?” survey questions designed by Otter, Seipel, Graeff, Alexander, Boraiko, Gray, Petersen and Sadler (2013) were 
replicated. The authors administered surveys to faculty and students in a large public southeastern university in the United States. The goal of the survey was to obtain opinions about online courses versus traditional ones. Faculty and students selected for the survey had to have experienced both online and traditional classroom learning. Students were asked questions about their general opinion of the two learning environments and were later asked to evaluate their experiences with the online versus traditional classroom. Faculty members were also asked to compare their experiences with teaching online versus face-to-face. This study did not assume that respondents have had any online experience. As a result the researcher replicated only those questions administered to students that inquire about their general perceptions of the two mediums of learning.

\section{Table 1}

Survey sections and relevant existing survey research

\begin{tabular}{ll}
\hline Survey sections & Adapted from \\
\hline Demographics & Self \\
Readiness for online learning & (McVay 2000, 2001; Hung et al., 2010) \\
Andragogy integration & (Christian, 1982) \\
Online versus traditional learning & (Otter et al., 2013) \\
\hline
\end{tabular}

In the end, since majority of the survey items or questions for this study were replicated from existing surveys (and in some cases were modified slightly), their reliabilities had already been affirmed in those studies. However, to further ensure reliability, the surveys were administered to 10 respondents, some of who took part in the pilot study (Tetteh-Richter, 2014). 
The survey instrument was also piloted among faculty members on dissertation committee. Feedback from pilot group led to further modification of instrument to eliminate identified problems such as double barrel questions, redundant questions and culturally insensitive questions.

\section{Procedures}

\section{Data collection}

Social media forums such as Facebook, Twitter and LinkedIn were used to solicit respondents. The Snowball Method was also used where survey-takers are encouraged to invite other potential respondents to participate in the survey. In addition to the above, faculty members in Ghanaian universities were contacted to announce the survey to their students. Constant reminders were sent on social media sites to encourage the participants to participate in the survey. The advantage of using an online survey was that it made it easy to determine the number of surveys that had come in each time, thereby signaling to the researcher to up the ante on spreading the word or close the survey for the next phase because target had been met.

The survey was opened for a little over two months, a suitable time for which significant data was collected. Participants were informed that participating in the survey led to a prize. Participants were initially informed of winning one out of four $50 \mathrm{GhC}$ worth of phone units. After two weeks of slow participants responses, the number of winners was hiked from four to ten. This was a move to increase more participants' chances of winning and, to encourage more participants' responses. Ten respondents were randomly selected in the raffle draw as winners of 50 GhC worth of phone units. The survey questions were such that respondents were not under duress and were assured their responses in no way affected the raffle draw.

Qualtrics was the online survey software used to administer the instrument. Qualtrics automatically generated an ID which was associated with every survey response. These 
Response IDs were used for the prize draw. Participants were asked at the end of the survey to children also provide their emails (optional) so they would be contacted if they won the prize draw. At the end of a little over two month time frame, the survey was closed and data analysis commenced.

\section{Data analysis}

Responses from the survey were first imported into the Statistical Package for Social Sciences (SPSS). The SPSS version 21 version was used to analyze data for this research. In SPSS, the first step of the analysis was to measure the internal consistency of the survey items. When the Cronbach's Alpha was greater than 0.7, this suggested a high degree of interrelatedness among the items in each section. This indicated further that statistical analysis could proceed. However, when the Cronbach's Alpha was low, it would have been useful to run an "item-total statistics" to determine if the "Cronbach's Alpha if Item Deleted" column revealed any improvement in the Cronbach's Alpha value once an item was dropped. A low Cronbach's Alpha could have been due to the fact that some of the items did not measure the same latent construct as the other items. In this scenario, a Factor Analysis would have helped identify components among sets of items within the questionnaire. Re-running the Cronbach’s Alphas on interrelated items revealed high coefficiencies, thus ensuring reliability (Cronbach, 1947).

The Likert survey items were also assigned numerical values with "strongly disagree" obtaining a numerical value of 1 , while "strongly agree" a numerical value of 5 . Respondents who score high on the scale were those that agree with the survey item. Statistical analysis was conducted via descriptive and nonparametric statistics. Tables and graphs were also employed to facilitate data presentation.

The demographical data (gender, age, marital status, school enrollment status, employment status, level of education, and number of in the home) were analyzed with 
descriptive statistics and presented in table format to give the reader a visual description of the demographic composition of respondents. The descriptives were gathered from questions one (1) through nine (9) in the first section of the survey instrument. These descriptors include frequencies, percentages and averages that were helpful in determining differences and similarities among the different groupings. These also helped in determining whether there were any statistical differences between the various categories.

The second section of the questionnaire was derived from research question one (RQ1) which attempted to measure the respondent's perception to adult learners’ readiness for online instruction. Tables and numbers were used to present participant responses. Percentages would aggregate findings, allowing the reader a cursory review of the prominent characteristics of the data. Nonparametric tests were used to compare the mean scores between the groups: gender (male vs female); age groups (young, middle or older adults), marriage status (single, married or divorced), and school enrollment status (enrolled or not), employment status (employed or unemployed) and child bearing status (parents or not).

The third section of the questionnaire was based on RQ2 which posed questions on andragogy. Likert scale questions were used to gauge students’ perceptions about their instructors' teaching methods, whether they used andragogy or not. The final section of the survey also employed Likert scale questions to determine whether respondents perceived online instruction as a viable alternative to traditional learning. For these sections, the measurements of central tendencies (mean) were used to identify frequent responses. Responses among groups of respondents (example gender) were compared using analysis of variance methods, such as the Mann Whitney or Kruskal Wallis tests.

\section{Table 2}

Research questions, data/survey items and data analysis 


\begin{tabular}{lll}
\hline RQ & Survey item descriptions & Analysis \\
\hline Demographics & Gender, Age, School Enrollment & Descriptive Statistics and \\
& status, Marriage status, Child & Graphs \\
& bearing status, Number of children & \\
& Readiness for online learning & Descriptive statistics \\
& & Mann-Whitney and K-W \\
& & Tests \\
& Andragogy integration & Descriptives, Mann- \\
& & Whitney \& K-W Tests \\
& & Descriptive statistics- \\
& Online versus traditional learning & Mann-Whitney \& K-W \\
& & Tests \\
\hline
\end{tabular}

\section{Methodological Limitations}

One limitation of the study was its reliance on an online medium for data collection. It was difficult to ensure that respondents who were invited for the study actually end up completing the study. The researcher was not able to administer paper surveys because of the location of the sample and was therefore limited to this medium. To mitigate this limitation, the researcher invited a large number of respondents to the survey with the hope that a significant portion of invitees would take the survey. The researcher used social media such as Facebook, LinkedIn, and Twitter, as well as college announcements to encourage respondents to participate in survey. 
Another limitation of the study was that the instruments, though replicated, were modified significantly by the researcher for the purpose of this study and therefore had not stood the test of time. To reduce this limitation, the researcher administered the survey to respondents who participated in the pilot study. Suggestions were also made by faculty on the dissertation committee about sections of the survey and questions were amended accordingly (TettehRichter, 2014). 


\section{CHAPTER 4: Results}

\section{Introduction}

In light of the issues raised above: a) the fact that adult learners are returning to the college classroom, b) the reality that universities in Ghana have limited infrastructural resources, and are therefore unable to effectively meet the demand for their services, and c) the fact that distance education would provide invaluable options for adult learners, among other factors, there remains the need to determine the viability of online instruction in Ghanaian universities from the perspective of the Ghanaian adult learner.

Hence, using a survey instrument, this study sought to aggregate the perceptions of Ghanaian adult learners on how successful online instruction will be in Ghana. The instrument was developed based on a combination of existing surveys (see Table 1 and Table 2). Overall, the survey had four (4) sections. Section one contained seven (7) demographic items which had questions on gender, age, marital status, educational background, enrollment and employee status and, whether respondents had or not. The second section contained thirteen (13) items geared towards answering research question one (RQ1) and had questions aimed at measuring perceptions on how ready adult learners were for online instruction/learning. The third and fourth sections had nineteen (19) and nine (9) items respectfully; the third section attempts at answering research questions two (RQ2) on their perception of whether Ghanaian faculty integrated andragogy in their teaching and section four intended to answer research question three (RQ3), which seeks the perceptions of online verses traditional learning. The survey instrument had forty eight (48) items total and took approximately twenty minutes to answer.

The overall rationale for this chapter is to present a detailed overview of the statistical results for this study and how data was organized and analyzed. 


\section{Organization of Data Analysis}

The section provides the statistical context for understanding the perceptions of adult learners' on online instruction in higher education. It first presents the statistical results on the survey items used and how reliable they were, followed by how the items address the research questions. Next, the section provides descriptive statistics on the demographic data of the participants. And then, addresses the research questions by the hierarchical order in which they appeared, that is, RQ1, followed by RQ2 and then RQ3. The chapter further elaborates on the relationship between variables using descriptive statistics and nonparametric tests such as MannWhitney $\boldsymbol{U}$ and Kruskal-Wallis tests to ascertain whether there were any differences between various dependent and independent variables. Finally, the chapter summarizes key findings from the data analysis.

Internal consistency and reliability. It is pertinent to reiterate that items for the instrument were adopted from existing surveys and scrutinized further for a reliability test. This was to ensure that data was worth the time and, consistent enough for further statistical analysis.

Demographic items such as age, gender, employment status, marital status, enrollment status, and educational background were set by the researcher and tested by 10 participants from a pilot study and committee members, all other items were adapted and some modified a little to fit participants comfort. Items for the first research question (RQ1) which measured "readiness" for online instruction was replicated from McVay (2000, 2001). Of the 13-item survey (McVay 2000, 2001) all were adopted with the exception of one question asking respondents to compare online learning to traditional learning. Since this question was addressed in another section of the questionnaire, it was eliminated and replaced with a question from Hung et.al (2010) to still make up for McVay’s (2000, 2001) instrument showed a satisfactory level of reliability 
(Cronbach's alpha $(\alpha)=.80)$. The instrument consist of a five-point Likert scale ranging from five (5) representing strongly agree to one (1) representing strongly disagree.

The instrument for measuring the second research question (RQ2) were adopted from Christian (1982) Student Oriented Questionnaires (SOQ) that was made up of fifty statements of which twenty five were andragogical and twenty five pedagogical. The statements were randomly listed on the questionnaire and consist of a five-point Likert scale ranging from five representing strongly agree to one representing strongly disagree. For the purpose of this study only the twenty five questions on andragogy were adopted and further narrowed down to nineteen items.

Survey questions designed by Otter, et al. (2013) are replicated to answer research question three. The goal of the survey was to obtain opinions about online courses versus traditional ones. Although the initial instrument was created to measure both faculty and students learning experiences online and in traditional classroom, this study adopted only the students experience items. The specific questions Otter, et al. (2013) used was on a Likert which recorded using a seven-point scale, where one = "strongly disagree" and seven= "strongly agree." For the sake of uniformity, this study reduced the scale from a seven point to a five point, just like the other.

Although main parts of this survey was replicated from existing surveys, the instrument was still passed through a reliability test. Results on the measure of reliability and internally consistent for the various items on the survey are presented below. Cronbach's alpha was measured to determine whether the internal consistencies (a measure of reliability) of the items on the Likert scale were measuring the same underlying construct.

Cronbach alphas $(\alpha)$ results for underlying constructs 'readiness', 'andragogy' were excellent (Cronbach's alpha $(\alpha)=.90)$ and the “Traditional Vs Online' $($ Cronbach's alpha $(\alpha)=$ .60) had an acceptable internal consistency. Scale means were $4.10(S D=.60)$ for 'readiness,' 
$3.00(S D=.60)$ for 'andragogy' integration, and $3.10(S D=.50)$ for 'traditional vs. online.' The means, standard deviations and alphas ( $\alpha$ ) were comparable to those obtained in previous studies (see Christian, 1982; McVay, 2000, 2001; Otter et al., 2013).

Tests of normality. After data collection and clean up, the datasets were subjected to a normality test. The test of normality was used to check whether the dependent variables were approximately normally distributed for each category of the independent variables. And, to ascertain how the datasets differed significantly compared to a normal distribution and whether or not data could be described as normally distributed data. Results from the analysis are shown below (Table 3).

The Kolmogorov-Smirnov (K-S) test was used to check whether the dependent variables were approximately normally distributed for each category of the independent variables. The test result as shown in Table 3 below:

\section{Table 3}

Tests of Normality Output

\begin{tabular}{lccc}
\hline & \multicolumn{3}{c}{ Kolmogorov-Smirnov $^{\mathrm{a}}$} \\
\cline { 2 - 4 } Variable & Statistic & $\mathrm{df}$ & Sig. \\
\hline Readiness & .12 & 411 & .00 \\
Andragogy & .08 & 411 & .00 \\
Tradition Vs Online & .09 & & .00 \\
\hline
\end{tabular}

a. Lilliefors Significance Correction 
K-S test results (Table 3 ) showed that the test for each dependent variable were significant ( $p$ $<.05)$. This implies the assumption of normality for 'readiness, andragogy and, traditional vs. online' scores were not satisfied for all group combinations of the independent variables, and were violated as assessed by K-S test $(p<.05)$ as shown above.

Therefore, since the assumptions of normality was violated, it was ideal for the researcher to use an alternative nonparametric test to compare differences in the datasets.

\section{Descriptive Characteristics of the Respondents}

The following section presents the summarized descriptive data results to help describe and summarize the data into a comprehensive data set. The descriptive analysis made use of the frequencies and percentages of the respondents' data. Most of the data output were rounded up to the nearest two decimal, this made some of percentages not add up to hundred (100) percent.

\section{Table 4}

Demographics of participants and their respective percentages (in the parenthesis)

\begin{tabular}{lr}
\hline & \multicolumn{1}{c}{ Participants } \\
Characteristic & $\mathrm{N}=420$ (Percent) \\
\hline $\begin{array}{l}\text { Gender } \\
\text { Male }\end{array} \quad$ Female & $250(60)$ \\
Age groups & $169(40)$ \\
21 yrs - 30 yrs & $93(22)$ \\
31 yrs - 40 yrs & $250(60)$ \\
41 yrs -50 yrs & $71(17)$ \\
51 yrs - above & $6(1)$ \\
Yes & $111(26)$ \\
No & $308(73)$ \\
Yes & $367(87)$ \\
No & $52(12)$ \\
\hline
\end{tabular}


Overall, the sample $(N=420)$ were selected from Gmail, Facebook and LinkedIn friends' lists of the researcher and others through snowballing. The sample consisted of mostly males $(60 \% ; n=$ 250), and females ( $40 \% ; n=169)$ made up the minority. Of the four hundred and twenty respondents (420), the ages ranged from 21 to above 51 years old, with the ages between 31 years and 40 years making up the majority (60\%). Most of the respondents were not enrolled (73\%) in any institutions of higher education as of the time of taking the survey. Majority were employed (87\%) at the time though (see Table 4 above).

\section{Table 5}

Demographics of participants and their respective percentages (in the parenthesis)

\begin{tabular}{lr}
\hline Characteristic & Participants \\
Educational background & \\
Undergraduate & \\
Master’s & $171(41)$ \\
PhD/doctoral & $197(47)$ \\
Other certificate & $22(5)$ \\
Marital status & $29(7)$ \\
Single & \\
Married & $161(38)$ \\
Divorced & $242(58)$ \\
& $16(4)$ \\
With & \\
Yes & \\
No & $231(55)$ \\
\end{tabular}

From Table 5 above, majority of the respondents had a Master's degree (47\%), closely followed by undergraduate degree (41\%) holders. Most of the respondents were married (58\%) and had (55\%) at home. Next is a look at the nonparametric results. 


\section{Nonparametrics}

This section presents research results categorized within each research question. The various statistical analyses are presented according to the hierarchical order of the research questions.

\section{Table 6}

Descriptive statistics of survey items for research question 1

\begin{tabular}{|c|c|c|c|c|c|}
\hline Items & $N$ & Min. & Max. & $M$ & $S D$ \\
\hline easy access to the Internet. & 420 & 1 & 5 & 4.33 & 0.94 \\
\hline Communicate with classmates & 419 & 1 & 5 & 4.30 & 0.85 \\
\hline Communicate with professors & 419 & 1 & 5 & 4.24 & 0.87 \\
\hline $\begin{array}{l}\text { willing to dedicate } 8 \text { to } 10 \text { hours per week for my } \\
\text { studies }\end{array}$ & 419 & 1 & 5 & 4.10 & 0.92 \\
\hline easy to set aside reading and homework time & 420 & 1 & 5 & 3.50 & 1.07 \\
\hline manage my study time effectively & 419 & 1 & 5 & 3.70 & 0.94 \\
\hline easily complete assignments on time. & 420 & 1 & 5 & 3.84 & 0.87 \\
\hline enjoy working independently. & 419 & 1 & 5 & 3.68 & 1.06 \\
\hline set goals. & 419 & 1 & 5 & 4.11 & 0.84 \\
\hline Microsoft Office programs & 420 & 1 & 5 & 4.38 & 0.81 \\
\hline $\begin{array}{l}\text { confident in using the Internet (example Google, } \\
\text { Yahoo, Bing) to find information. }\end{array}$ & 419 & 1 & 5 & 4.64 & 0.73 \\
\hline $\begin{array}{l}\text { confident in using online tools (email, to } \\
\text { communicate with others. }\end{array}$ & 418 & 1 & 5 & 4.62 & 0.76 \\
\hline $\begin{array}{l}\text { confident in expressing myself (emotions and } \\
\text { humor) through writing. }\end{array}$ & 418 & 1 & 5 & 4.26 & 0.86 \\
\hline Readiness & 420 & 1.08 & 5 & 4.13 & 0.57 \\
\hline
\end{tabular}

Research question 1. Table 6 below show the descriptive statistics on all items. It contains the population sample size $(N)$, Likert minimum (Min.) and maximum (Max.), the means 
$(M)$ and, the standard deviation (SD). The dependent variable (Readiness) output data is also shown at the bottom of the table.

Thirteen (13) items were used to access respondents' perception of adult learners' readiness for online instruction. The average response $(M=4.10, S D=.60)$ of the participants on the 'readiness' for online instruction showed that they perceived themselves or adult learners to be ready for online instruction. On the scale of 1 to $5,1=$ strongly disagree, $5=$ strongly agree, the majority participants leaned toward agreed, which is quite close to the maximum agreement level of the research question. That is, the higher the mean $(M)$ score, the more participants perceived adult learners as ready.

A Mann-Whitney U test was run to determine if there were differences in 'readiness' score between males and females. 'Readiness' scores for males (mean rank $=212.41)$ and females (mean rank $=206.44$ ) were not significantly different, $U=20523.50, z=-.50, p=.60$. This means that, male and female participants did not differ in their perception for readiness of online instruction.

A Kruskal-Wallis $\mathrm{H}$ test was run to determine if there were differences in readiness score between four groups of participants with different age groups: the "21 - 30 years ", "31 - 40 years ", "41 - 50 years " and "51 years - above " age groups. Distributions of readiness scores were not similar for all groups. The mean rank of readiness scores was not significantly different between groups, $\chi^{2}(3)=4.70, p=.20$. These results indicated that, age differences were perceived to make no difference on adult learners’ readiness for online instruction.

Similarly, the Mann-Whitney U test was used to determine if there were differences in 'readiness' score between the enrolled and non-enrolled students. Readiness scores for enrolled (mean rank $=217.17)$ and non-enrolled (mean rank $=207.42)$ were not significantly different, $U$ 
$=16298.00, z=-.7, p=.50$. That is, being enrolled in university at the time of the survey had no influence on 'readiness.'

Also, a Kruskal-Wallis $\mathrm{H}$ test to determine if there were differences in readiness score between 3 groups of participants with different marital status: the "single ", "married ", and "divorced" status was performed. Distributions of readiness scores were not similar for all groups. The mean rank of readiness scores was not significantly different between groups, $\chi^{2}(2)$ $=1.60, \mathrm{p}=.50$. This means that, marital status has no impact on adult learners' readiness for online instruction.

A Mann-Whitney U test was run to determine if there were differences in 'readiness' score between those who had children and those who did not. Distributions of the 'readiness' scores for those who had children and those who did not were not similar, as assessed by visual inspection. Readiness scores for children (mean rank $=214.34$ ) and no children (mean rank = 204.67) were not significantly different, $U=20711.50, z=-.10, p=.40$. Having children or not has nothing to do with adult learners’ readiness for online instruction.

Finally, a Kruskal-Wallis $\mathrm{H}$ test to determine if there were differences in readiness score between 4 groups of participants with different levels of education degree certificates: the "undergraduate", "Master’s", "PhD” and “some other certificate” was performed. Distributions of readiness scores were similar for all groups. The mean rank of readiness scores was significantly different across groups, $\chi^{2}(3)=10.50, p=.02$. (See Table 7). This means, the level of educational background does affect an adult learners' readiness for online instruction. As indicated in Table 7, participants had the perception that higher levels of education did affect adult learners' readiness for online instruction (Table 7). 


\section{Table 7}

Levels of Educational background as Compared to Readiness

\begin{tabular}{llrrr}
\hline Variable & Education & $\mathrm{N}$ & & Mean Rank \\
\hline \multirow{3}{*}{ Readiness } & Undergraduate & 171 & & 211.80 \\
& Master's & 197 & & 215.90 \\
& PhD / doctoral & 22 & 233.02 \\
& Some other certificate & 29 & 141.81 \\
& Total & 419 & \\
\hline
\end{tabular}

Chi-Square $\quad 10.529$

Df 3

Asymp. Sig. $\quad .015$

a. Kruskal Wallis Test

b. Grouping Variable: Education

Research question 2. Table 8 below, shows the descriptive statistics on all items. It contains the population sample size $(N)$, Likert minimum (Min.) and maximum (Max.), the means (M) and, the standard deviation (SD). The dependent variable (Andragogy) output data is also shown at the bottom of the table. Descriptive results for the items are shown in Table 8 below.

Nineteen (19) items were used to access respondents' perception of adult learners' on the integration of andragogy in instruction. The average response $(M=3.0, S D=.60)$ of the participants on the integration of 'andragogy' for online instruction showed that most did not agree or disagree on this question. On the scale of 1 to 5, $1=$ strongly disagree, $5=$ strongly agree, the majority participants leaned toward "I'm not certain about this statement to agree or disagree." 
Table 8

Descriptive statistics of survey items for research question 2

\begin{tabular}{|c|c|c|c|c|c|}
\hline Items & $\mathrm{N}$ & Min. & Max. & M. & SD \\
\hline Instructor: information as absolute truth & 420 & 1 & 5 & 3.44 & 0.96 \\
\hline $\begin{array}{l}\text { Instructor: encourages me to examine my feelings, } \\
\text { attitudes and behaviors. }\end{array}$ & 420 & 1 & 5 & 3.09 & 1.04 \\
\hline $\begin{array}{l}\text { Instructor: allows me to actively participate in } \\
\text { deciding what is to be learned and how it is to be done. }\end{array}$ & 420 & 1 & 5 & 2.95 & 1.15 \\
\hline $\begin{array}{l}\text { Instructor: obtains suggestions from me on how to } \\
\text { improve his/her teaching. }\end{array}$ & 420 & 1 & 5 & 2.78 & 1.22 \\
\hline $\begin{array}{l}\text { Instructor: shows me that my abilities and experiences } \\
\text { are respected and valued. }\end{array}$ & 419 & 1 & 5 & 3.15 & 1.19 \\
\hline Q11_6R (see Appendix A) & 420 & 1 & 5 & 2.10 & 0.79 \\
\hline Q11_7R (see Appendix A) & 420 & 1 & 5 & 2.76 & 1.05 \\
\hline Q11_8R (see Appendix A) & 420 & 1 & 5 & 2.23 & 1.04 \\
\hline $\begin{array}{l}\text { Instructor: takes time to develop a friendly and } \\
\text { cooperative atmosphere in the classroom. }\end{array}$ & 420 & 1 & 5 & 3.20 & 1.09 \\
\hline Instructor: allows me to evaluate his/her achievement. & 419 & 1 & 5 & 2.79 & 1.18 \\
\hline $\begin{array}{l}\text { Instructor: discusses his/her learning blunders with } \\
\text { me. }\end{array}$ & 419 & 1 & 5 & 2.34 & 1.09 \\
\hline $\begin{array}{l}\text { Instructor: treats me as competent to choose and carry } \\
\text { out my own projects for learning. }\end{array}$ & 420 & 1 & 5 & 3.13 & 1.13 \\
\hline $\begin{array}{l}\text { Instructor: provides students with opportunities to } \\
\text { develop warm relationships with him/her. }\end{array}$ & 419 & 1 & 5 & 3.22 & 1.05 \\
\hline Q11_14R (see Appendix A) & 418 & 1 & 5 & 2.89 & 1.12 \\
\hline Q11_15R (see Appendix A) & 419 & 1 & 5 & 2.51 & 0.97 \\
\hline Andragogy & 420 & 1.16 & 4.16 & 2.88 & 0.60 \\
\hline
\end{tabular}

A Mann-Whitney U test was run to determine if there were differences in 'andragogy' score between males and females. Distributions of the 'andragogy' scores for males and females were not similar, as assessed by visual inspection. Andragogy scores for male (mean rank = 212.20) and female (mean rank $=206.80$ ) were not significantly different, $U=20581.0, z=-.45$, $p=.7$ 
A Kruskal-Wallis $\mathrm{H}$ test to determine if there were differences in andragogy score between 4 groups of participants with different levels of education backgrounds the "21 - 30 years ", "31 - 40 years ", "41 - 50 years " and "51 years - above " age groups. Distributions of andragogy scores were similar for all groups. The mean rank of andragogy scores was not significantly different across groups, $\chi^{2}(3)=.50, p=.90$. This means that, the level of educational background had no impact on adult learners' perception integration of andragogy in online instruction.

The Mann-Whitney U test for differences in ‘andragogy’ score between those enrolled and non-enrolled were not similar. Andragogy scores for the enrolled (mean rank $=209.30$ ) and non-enrolled (mean rank $=210.20$ ) were not significantly different, $U=17020.00, z=-.07, p=$ .90. That means, school enrollment made no impact in terms of whether andragogy was integrated in instruction or not.

A Kruskal-Wallis $\mathrm{H}$ test to determine if there were differences in andragogy score between three groups of participants with different levels of marital status: the "Single", "Married" and "Divorced" was performed. Distributions of andragogy scores were similar for all groups. The mean rank of andragogy scores was not significantly similar between groups, $\chi^{2}$ (2) $=1.10, \mathrm{p}=.60$. This means that, the level of marital status had no impact on adult learners' perceptions on integration of andragogy in online instruction.

A Mann-Whitney U test was run to determine if there were differences in 'andragogy' score between those with children and those with none. Distributions of the 'andragogy' scores for those with and no were not similar. Andragogy scores for those with (mean rank = 203.6) and no (mean rank =217.90) were not significantly different, $U=20225.50, z=-1.20, p=.20$.

A Kruskal-Wallis $\mathrm{H}$ test to determine if there were differences in andragogy score between 4 groups of participants with different levels of education backgrounds: the 
"undergraduate", "Master’s", "PhD” and “some other certificate” was performed. Distributions of andragogy scores were similar for all groups. The mean rank of andragogy scores was significantly similar between groups, $\chi^{2}(3)=.80, p=.90$. This means, the level of educational background had no impact on adult learners' perception integration of andragogy in online instruction.

A Mann-Whitney U test was run to determine if there were differences in 'andragogy' score between those employed and those not employed. Distributions of the 'andragogy' scores for those employed and those not employed were not similar. Andragogy scores for those employed (mean rank $=203.60$ ) and those not employed (mean rank $=217.90$ ) were not significantly different, $U=20225.50, z=-1.20, p=.20$.

Research Question 3. Table 9, below, shows the descriptive statistics on all items. It contains the population sample size ( $N$ ), Likert minimum (Min.) and maximum (Max.), the means $(M)$ and, the standard deviation (SD). The dependent variable (TraditionalVsOnline) output data is also shown at the bottom of the table. Descriptive results for the items are shown in Table 9.

Nine (9) items were used to access respondents 'perception of adult learners' on what they preferred, traditional verses online learning when it came to instruction. The average response $(M=3.1, S D=.50)$ of the participants' preference for instruction (i.e, TraditionalVsOnline ) showed that most could not pick a side. On the scale of 1 to 5, $1=$ strongly disagree, 5 = strongly agree, the majority participants leaned toward "I'm not certain about this statement to agree or disagree." Details below shed more light on this finding. 


\section{Table 9}

Descriptive statistics of survey items for research question 3

\begin{tabular}{llcccc}
\hline Items & $\mathbf{N}$ & Min. & Max. & M & SD \\
\hline $\begin{array}{l}\text { Online courses provide a better learning experience } \\
\text { than traditional courses. }\end{array}$ & 408 & 1 & 5 & 3.00 & 1.04 \\
$\begin{array}{l}\text { Online courses require more of a student's time than } \\
\text { traditional courses. }\end{array}$ & 409 & 1 & 5 & 3.42 & 1.10 \\
$\begin{array}{l}\text { An online course does not really need a teacher - it } \\
\text { usually ends up being "self- directed learning." }\end{array}$ & 411 & 1 & 5 & 3.40 & 1.04 \\
$\begin{array}{l}\text { The overall quality of online courses is better than that } \\
\text { of traditional courses. }\end{array}$ & 409 & 1 & 5 & 2.83 & 1.01 \\
$\begin{array}{l}\text { The amount of material that is presented to students in } \\
\text { an online course is greater than in a traditional course. }\end{array}$ & 410 & 1 & 5 & 3.48 & 0.94 \\
$\begin{array}{l}\text { Q12_6R } \\
\text { Students receive better quality teaching from online }\end{array}$ & 406 & 1 & 5 & 3.14 & 1.03 \\
$\begin{array}{l}\text { courses than they receive from traditional courses. } \\
\text { Q12_8R }\end{array}$ & 405 & 1 & 5 & 2.86 & 1.01 \\
$\begin{array}{l}\text { Students learn more in online courses than they learn } \\
\text { in traditional courses. }\end{array}$ & 405 & 1 & 5 & 2.55 & 1.06 \\
\hline \begin{tabular}{l} 
TraditionalVsOnline \\
\hline
\end{tabular} & 411 & 1 & 5 & 3.07 & 1.03 \\
\hline
\end{tabular}

A Mann-Whitney U test was run to determine if there were differences in 'traditionalvsonline' score between the male and female. Distributions of the ‘traditionalvsonline’ scores for male and female were not similar (as assessed by visual inspection on Table 8 below). TraditionalvsOnline scores for male (mean rank $=194.50)$ and female (mean rank $=221.30$ ) were significantly different, $U=17672.00, z=-2.30, p=.02$ (Table 7). This implies that gender has an impact on making choices between traditional instruction and online instruction. Females (mean rank $=221.30)$ perceived online instruction a better alternative to traditional instruction as compared with males (mean ranks $=194.50$ ). 


\section{Table 10}

TraditionalvsOnline scores

\begin{tabular}{llrrr}
\hline Variable & Gender & N & Mean Rank & Sum of Ranks \\
\hline \multirow{4}{*}{ TraditionalVsOnline } & Male & 242 & 194.52 & 47075.00 \\
& Female & 168 & 221.31 & 37180.00 \\
& Total & 410 & & \\
\hline
\end{tabular}

\begin{tabular}{lr}
\hline Mann-Whitney U & 17672.000 \\
Wilcoxon W & 47075.000 \\
Z & -2.256 \\
Asymp. Sig. (2- & .024 \\
tailed) & \\
\hline
\end{tabular}

a. Grouping Variable: Gender

A Kruskal-Wallis $\mathrm{H}$ test to determine if there were differences in 'traditionalvsonline' score between 4 groups of participants with different levels in ages: the "21 - 30 years ", "31 40 years ", "41 - 50 years " and "51 years - above " age groups. Distributions of 'traditionalvsonline’ scores were similar for all groups. The mean rank of 'traditionalvsonline' scores was similar between groups, $\chi^{2}(3)=3.8, p=.30$. This means that, age differences had no influence on adult learners’ perceptions when comparing online with traditional instruction.

A Mann-Whitney U test was run to determine if there were differences in 'traditionalvsonline' score between the enrolled and not enrolled. Distributions of the 'traditionalvsonline' scores for the enrolled and not enrolled were not similar, as assessed by visual inspection. TraditionalvsOnline scores for the enrolled (mean rank $=202.55$ ) and not enrolled (mean rank $=206.54$ ) were not different, $U=15895.00, z=-.3, p=.8$. School enrollment had no influence on choice of instructional delivery. 
A Kruskal-Wallis $\mathrm{H}$ test to determine if there were differences in 'traditionalvsonline' score between 3 groups of participants with different levels in marital status: the "single ", "married ", and "divorced" status. Distributions of traditionalvsonline scores were similar for all groups. The mean rank of 'traditionalvsonline' scores was similar between groups, $\chi^{2}(2)=4.50$, $p=.10$. Marital status has no impact on choice of instructional delivery.

A Mann-Whitney U test was run to determine if there were differences in ‘traditionalvsonline’ score between those with children and those who had no children. Distributions of the 'traditionalvsonline' scores for those children and those who had no children were not similar, as assessed by visual inspection. TraditionalvsOnline scores for those with (mean rank $=212.20)$ and no (mean rank $=197.20)$ were not significantly different, $U=$ 19257.00, $z=-1.30, p=.20$. The number of children one had made no difference in comparing choice of instructional delivery.

A Kruskal-Wallis $\mathrm{H}$ test to determine if there were differences in 'traditionalvsonline' score between 4 groups of participants with different levels of educational backgrounds: the "undergraduate", "Master’s", "PhD” and “some other certificate” levels. Distributions of 'traditionalvsonline' scores were similar for all groups. The mean rank of 'traditionalvsonline' scores was significantly similar between groups, $\chi^{2}(3)=5.80, p=.10$. This means that, level of education has no impact on adult learners' perceptions when comparing online with traditional instruction.

\section{Summary}

To this end, detailed data has shown that when it came to the perceptions on 'readiness,' respondents agreed that most adult learners were ready for online instruction. However, their perceptions on the integration of andragogy and, whether they preferred traditional instruction to 
online instruction remained neutral. In contrast, there were significant differences on 'readiness' at different levels of education. Respondents were of the view that level of education definitely impacted one's readiness for online instruction. Also, gender did impact the choice of media for instruction. Females seemed to favor online more than males. The proceeding chapter sheds more light on the findings, implications, conclusion and further research. 


\section{CHAPTER 5}

\section{FINDINGS, CONCLUSIONS, AND IMPLICATIONS}

\section{Introduction}

This chapter provides a summary of the findings, implications and conclusions of the study, and then provides recommendations for further study. From the beginning, the researcher was interested in determining whether certain dependent and independent variables played any role on the perception of adult learners' readiness for online instruction in Ghanaian higher education. Rather than placing the Ghanaian adult learner in the “one-size-fits-all” paradigm, this study focused on finding out the degree of variability in the perceptions of adult learners across three different perspectives (readiness, andragogy and, online verses traditional instruction). This chapter elaborates and concludes on key findings of this study.

\section{Summary of the Study}

The study was conducted with Ghanaian adults who had at least an undergraduate degree from a Ghanaian university and therefore had extensive knowledge of the Ghanaian higher education system. Participants were recruited on social media sites such as Facebook and LinkedIn. 1200 emails were sent out over a period of 2 months. Participants who responded to emails were asked to share survey link on their Facebook pages after taking survey. The survey was closed when the target was met. By the end of the two month period, 530 responses had been collected.

The data was cleaned up and reverse coded in SPSS, resulting in the deletion of 110 incomplete responses, leaving 420 surveys for statistical analysis. Descriptive statistics, MannWhitney tests and Kruskall-Wallis tests were used to analyze the data. K-S test for normality showed distribution across all three dependent variables (readiness, andragogy and Online 
verses traditional) were violated. Since the assumptions of normality was violated, it behooved the researcher to use an alternative nonparametric test to compare differences across variables.

\section{Descriptive Characteristics of the Respondents}

Sixty percent of the population sample were males, leaving females $(40 \% ; n=169)$ in the minority. The age of participants ranged from 21 to 51 years old, with the majority being between 31 to 40 years (60\%). Most of the respondents (73\%) were not enrolled in any institution of higher education at the time of taking the survey. That said, almost half of participants had a Master's degree, while 41\% had a first degree demonstrating that they were equipped to share their views on the topic. Most of the respondents (87\%) were gainfully employed and more than half of them were married with children.

Research question 1. Lin and Hsieh (2001), noted that successful online students are those that are self-directed and take responsibility for their learning. Watkins, Leigh and Triner (2004) argued that students who demonstrate success in the conventional classroom may not necessarily succeed in the online environment for which reason; potential online students have to take a readiness assessment to determine their suitability for this medium of learning. Hung, Chou, Chen and Own (2010) support this conclusion — that distance educators have to set an evaluation system in place to allow learners to gauge their preparedness for online education.

Research Question One had the objective of measuring respondent's perceptions of their readiness for online education. The concept of readiness gauged students access to technology as well as their preparedness for self-directed learning as found in an online environment. A majority of respondents agreed that they were ready for online instruction $(M=4.1, S D=.60)$. This finding supports assertions by Brown (2005) and Mangesi (2007) that even though Ghana is a developing country, there is a concerted effort at the governmental level to ensure 
technological access in education. Results from the pilot study, regarding Ghana’s readiness for online education, were mixed — with a majority of respondents arguing that the technological infrastructure to support a fully functioning online program was absent. The findings from this study offer more hope as respondents overwhelmingly perceive themselves as being ready to explore online learning.

'Readiness' scores across gender did not show significant differences $(p=.60)$ between males (mean rank $=212.41)$ and females (mean rank $=206.44$ ) when it came to being ready for online instruction. In other words males are no more or less ready for online education than their female counterparts. This finding was pleasantly surprising as the researcher expected male respondents to express greater confidence in their readiness for online instruction. Males are often perceived as more technologically savvy than females and therefore the researcher is pleased to note that inequalities in access to technology appear to be diminishing in $21^{\text {st }}$ Century Ghana.

Findings from the study also reveal no statistical difference between the age groups ( $p=$ .20). This implies that based on this study, age is not a determinant of whether an individual is ready for online education. Survey respondents' ages ranged from 21 to 51, with the majority (82\%) of respondents falling within the 21 to 40 age group. The lack of variation in age distribution could be an explanatory factor for why age did not affect perceptions of readiness. Likewise, marital status and parenthood (number of children) did not show any significance visà-vis readiness. This suggests that one's marital status does not make an individual more or less ready for online education; neither does one's parental status (number of children) have an effect on readiness for online education. This finding is quite self-explanatory as one cannot expect there to be a correlation between one's marriage and parental status with one's readiness for online education. While the researcher expected that respondents with familial obligations (see 
discussion on research question three) would prefer the online model because it offers flexibility, it seems more far-fetched to expect a person to be better prepared for online education simply because of their familial obligations. Readiness for online education is based on access to technology, the Internet and the ability for an individual to learn independently. One's marital and parental status should not necessarily impact one’s readiness for online learning.

It does appear however that level of education does impact adult learners' readiness for online education $(p=.02)$. The higher the participant's educational background the more ready they were for online instruction. This supports Asunka (2008) who found that undergraduate Ghanaian university students expressed deep animosity toward online education, describing it as too complicate and time consuming. The author noted that this group of students preferred faceto-face interaction instead and hypothesized that students' dissatisfaction with the online model, specifically the asynchronous version, could be a result of "ill-structured" learning activities. The findings from the study show that respondents with Masters Degrees were perceived to be more ready than their undergraduate counterparts, thus lending credence to Asunka’s (2008) findings. Findings from the study also corroborate conclusions drawn by Cercone’s (2008)—that graduate level courses are more amenable to the online model. The implication is that for a successful online program in Ghana, tertiary institutions will need to start with graduate programs.

Research question 2. Nineteen (19) items were used to access respondents' perception of adult learners' on the integration of andragogy in instruction. The average response $(M=3.0$, $S D=.6$ ) of participants' perception on the integration of 'andragogy' for online instruction showed that most were indecisive on this question. On the scale of 1 to 5, 1 = strongly disagree, 5 = strongly agree, the majority participants leaned toward "I'm not certain about this statement to agree or disagree." (see Table 9 above). These findings were rather disappointing as the 
researcher expected that this study will echo findings from the pilot study that demonstrated that faculty in Ghana do not incorporate andragogical principles in curriculum development and instruction. The term "andragogy” was used in the pilot study and respondents were clueless about the concept even though, it was defined for them prior to the study. As a result the researcher adapted the Student Orientation Questionnaire (SOQ) created by Christian (1982) to gauge students’ perceptions about the extent to which andragogy were incorporated by the faculty. While Christian (1982) aimed to determine whether students preferred andragogical to pedagogical instructional methods, for which reason the author posed questions such as: “I feel the instructor should use group activities rather than such methods as lectures”, this study modified the question to a statement: “ $\quad$ Instructor uses group activities rather than such methods as lectures” and invited respondents to agree or disagree with that statement. Another way in which the SOQ was modified was that the list of questions was reduced and culturally sensitive questions were eliminated to ensure that Ghanaian respondents could relate to the questions and answer it accordingly. Despite the afore described efforts, respondents chose the option “I'm not certain about this statement to agree or disagree." While this researcher expected a more definitive response, this neutral choice favorite actually confirms that Ghanaian students are not exposed to andragogical teaching practices and as such are unable to offer comments on the subject. Respondents were unable to relate to statements such as the following because (per findings from the pilot study) faculty do not practice andragogy and do not design curriculum with the needs of the learners in mind:

1. The instructor encourages me to examine my feelings, attitudes and behaviors.

2. The instructor allows me to actively participate in deciding what is to be learned and how it is to be done.

3. The instructor obtains suggestions from me on how to improve his/her teaching. 
4. The instructor shows me that my abilities and experiences are respected and valued.

5. The instructor acts as if $\mathrm{s} / \mathrm{he}$ is responsible for motivating me to learn what $\mathrm{s} / \mathrm{he}$ wants me to learn.

6. The instructor takes time to develop a friendly and cooperative atmosphere in the classroom.

If students have not witnessed faculty perform the above listed actions, it is no wonder that the common response was: “I'm not certain about this statement to agree or disagree.” Based on the preceding results, it was therefore not surprising that a Mann-Whitney $U$ test to determine if there were differences in 'andragogy' scores between the male and female showed no statistical difference, $(p=.70)$. It was also not surprising that a Kruskal-Wallis $\mathrm{H}$ test to determine if there were differences in andragogy score based on educational background also failed to show statistical significance $(p=.90)$. Respondents’ level of educational had no impact on adult learners' perception of the extent to which andragogy is integrated in instruction because (the research contends) faculty members in Ghana fail to follow andragogical principles, regardless of the level of instruction (undergraduate, graduate, etc.). Perceptions on integration of andragogy were also not influenced by whether or not the respondent was currently enrolled in a tertiary program. Neither current nor previous students were "certain about this statement (measuring andragogy) to agree or disagree.” It will be beneficial for a follow up study that includes faculty in the respondents’ pool to determine whether they perceive their instructional methods as following the tenets of andragogy.

Research question 3. Nine (9) items were used to access respondents’ preference for traditional verses online learning. The average response $(M=3.1, S D=.5)$ of the participants on the 'traditionalvsonline’ spectrum showed that respondents were neutral in their evaluation of 
their preference for online versus traditional modes of learning. On the scale of 1 to 5, $1=$ strongly disagree, 5 = strongly agree, the majority of participants leaned toward "I'm not certain about this statement to agree or disagree. Findings from the data show that age has no impact on adult learners' preferences for online versus traditional instruction. Similarly, whether or not a respondent is currently enrolled in a school, married or parenting does not appear to impact preference for the online versus the traditional model. Finally, one's level of education did not appear to impact adult learners' preferences for online or traditional instruction. While these responses were not as definitive as this researcher hoped, they were not completely unexpected. The majority of respondents (73\%) were currently not enrolled in a university. Also, almost half of the respondents already had their Master's degree, suggesting that they may not be interested in pursuing further studies. Of the remaining half, $41 \%$ had their bachelors' degree. It is probable that most of these respondents are equally not looking to pursue graduate studies thereby resulting in their neutral responses. It is also worth noting that respondents (even for those who were currently enrolled in school), may not have had any experience with instruction in an online environment, thereby explaining their inability to definitively make a choice between the two mediums.

On a positive note, a Mann-Whitney $U$ test was run to determine if there were differences in 'traditionalvsonline’ score between the genders. Scores for male (mean rank $=194.5$ ) and female (mean rank $=221.3)$ were significantly different, $(p=.02$ (Table 7). This suggests that gender has an impact on students making choices between traditional and online instruction. Females (mean rank $=221.3$ ) were more likely to perceive online instruction as a better alternative to traditional instruction as compared with their male counterparts (mean ranks $=$ 194.5). This finding supports Kwapong (2007a) who saw online education as a good option for adult learners, especially for female married students, who because of societal norms about the 
role of women are unable to patronize school programs designed for nontraditional students that typically take place in the evenings. The author further noted that female students might be uncomfortable in late night study groups consisting primarily of male students. Kwapong (2007a) maintained that the traditional face-to-face educational system favors male students rather than their female counterparts and concludes that distance education programs would provide greater access to female students. The implication for this finding is that it will behoove university administrators in Ghana not just to develop graduate programs, but offer courses that are attractive to their female students. Targeting graduate female students will increase the likelihood of developing a successful online program in Ghana.

\section{Conclusions}

The purpose of this study was to investigate the perceptions of Ghanaian adult learners about the viability of online education in Ghana. Particularly, the study focused on adult learners' perception on (1) their readiness for online education, (2) extent to which andragogy is incorporated in online classes, and (3) to what degree (or whether) online education is as a viable alternative to traditional learning.

The three dependent variables: readiness, andragogy, and online versus traditional were evaluated based on the introduction of the following independent variables: gender, age, marital status, number of children, educational background, school enrollment status and employment status.

In a majority of cases, the introduction of the independent variables did not result in a significant change in the dependent variable. For instance, most of the respondents were ambivalent about the role that andragogy plays in instruction. None of the independent variables appeared to influence a change in the dependent variable, andragogy. In the case of readiness and traditional versus online models, the independent variables of education and gender appeared to 
make an impact. A majority of respondents agreed that adult learners in Ghana were ready for online education. The higher the participant's educational background the more ready they were perceived to be for online instruction. In addition, gender appeared to have an impact on the dependent variable, traditional versus online. Females were perceived to prefer online education to traditional face-to-face instruction. It is evident that adult learners, females, and graduate students in Ghana, are somewhat knowledgeable about online learning and are open to exploring this new phenomenon.

\section{Implications}

This study is of importance to policy makers, college faculty and administrators in the Ghana education system. The government recognizes that online learning is the wave of the future, given the inability of traditional universities to adequately cater for the increased demand for higher education. There have been discussions in the media by government officials about the possibility of introducing online learning. Thus far, no significant effort has been expended by the government to facilitate the implementation of this policy. As a nation, Ghana's universities do not train instructional technologists. The government appears to lack the expertise to spearhead this project. Research in this area, as it relates to Ghana, is minimal (Asunka, 2008). This study is timely and will add to the scarce literature in this field of online learning and distance education. It also provides useful information for policy makers about Ghanaian students' ability to succeed in an online environment. Asunka’s (2008) study demonstrated that the majority of students, most of whom were not adult learners, did not like the online model. However, the handful of adult learners in the class preferred this medium. This study, because it targeted adult learners in particular, expands upon Asunka’s (2008) study and provides valuable information to policy makers about how to implement online learning in Ghana. 
This study is also useful to college administrators as it provides valuable information about the types of students to target for potential future online classes. College administrators will also be equipped with information on how to design the ideal online classroom for adult learners in Ghana. It is the researcher's hope that findings from the study, will challenge administrators to start considering alternate teaching methods for adult learners—-methods that place the student at the center of learning. If administrators understand the value of andragogical instruction, and its potential to facilitate online learning, they may be motivated to challenge their faculty to break traditional patterns of teaching that focus primarily on pedagogical models.

Education in Ghana and most African countries, have placed the instructor at the center of teaching and learning. This paper joins the few voices that advocate for the clients; the consumers of education, i.e. the leaners. University education is becoming more competitive in Ghana. The state universities no longer have the final word. Students now can make choices, albeit limited, about whether to go to a state school or a private institution. The country is rapidly moving away from state-funded university education as cost of tuition is shifted to the student. The faculty member interviewed for the pilot study noted that the numbers of fee-paying students in university institutions are constantly increasing and this is welcome news for college faculty, administrators and the government. This has implications though: Students, because they are now spending a significant amount of their hard earned money on their education, may be more willing to challenge faculty and demand better quality of service. This paper allows policy makers, college faculty and administrators to hear the students' voice and hopefully revise current practices to ensure that instruction becomes more student-centered, thus preparing the Ghanaian university system for effectively implementing online learning. 


\section{Future Research}

This study is important because it fills the gap in research in the area of online learning in the developing world, specifically Ghana. That said, it is simply a starting point in the discussion. The researcher offers the following recommendations for future research.

1) Scholarship in this field will benefit from the replication of this study. A majority of respondents were not currently enrolled in an institution. It will be greatly beneficial to include a larger proportion of current students in the study as they will be in a better position to give an up to date evaluation of the nature of teaching and learning in Ghanaian universities.

2) The data from this study did not provide any conclusive evidence on the role of andragogy in instruction in Ghana. It is recommended that future research include faculty perceptions in the study. Respondents may have been ambivalent because they are not used to thinking about instructional methods and how they affect learning. Including faculty in the survey will allow us to gauge whether faculty actively or passively support andragogical principles in instruction.

3) As of last year, the University of Ghana was introducing an online component to the programs offered. It will be useful to conduct a study that includes students enrolled in an online program in Ghana to allow researchers a practical evaluation of the prospects and challenges of this model in a developing country such as Ghana. 


\section{References}

Ababio, K.A., Omane-Adjepong, M., Boateng, A., Aidoo, E.N., Pharikhan, S., Rashid F.A., Munyakazi, L., \& Nsowah-Nuamah, N. N. N. (2012). Perceptions of students towards tertiary weekend school in Ghana. Journal of Education and Practice, 3(12), 1-9.

Adei, S. (2006). Ghana. In GFME’s “A global guide to management education.”

Emerald Group Publishing, Ltd. Retrieved from:

http://www.docstoc.com/docs/133530564/Ghana-7378---GFME-Global-Foundation-forManagement-Education

Allen, I. E., \& Seaman, J. (2014). Grade change: Tracking online education in the United States. Babson Survey Research Group, Higher Education Reports. Retrieved from: http://www.onlinelearningsurvey.com/highered.html

Allen, I. E., \& Seaman, J. (2010). Class differences: Online education in the United States. The Sloan Consortium/Babson Survey Research Group. Sloan Consortium Survey of Online Education. Retrieved from: http://sloanconsortium.org/publications/survey/pdf/class_differences.pdf

Allen, I. E., \& Seaman, J. (2008). Staying the course: Online education in the United States. The Sloan Consortium/Babson Survey Research Group. Sloan Consortium Survey of Online Education.. Retrieved from: http://sloanconsortium.org/sites/default/files/staying_the_course-2.pdf.

Allen, I. E., \& Seaman, J. (2006). Making the grade: Online education in the United States, Needham, MA: The Sloan Consortium. Retrieved from http://www.sloanc.org/publications/survey/ pdf/making_the_grade.pdf 
Asunka, S. (2008). Online learning in higher education in Sub-Saharan Africa: Ghanaian university students' experiences and perceptions. International Review of Research in Open and Distance Learning, 9(3). Retrieved from: http://files.eric.ed.gov/fulltext/EJ815764.pdf

Bergsteiner, H., Avery, G. C., \& Neumann, R. (2010). Kolb's experiential learning model: critique from a modelling perspective. Studies In Continuing Education, 32(1), 29-46.

Boateng, K., \& Ofori-Sarpong, E. (2002). An analytical study of the labour market for tertiary graduates in Ghana, Accra. Retrieved from:http://siteresources.worldbank.org/EDUCATION/Resources/2782001099079877269/547664-1099079956815/Ghana_Labor_Market_tertiary_En02.pdf

Boissiere, M. (2004). Determinants of primary education outcomes in developing countries. Washington DC: A World Bank report. Retrieved from: http://www.worldbank.org/oed/education/documents/education_primary_rationale_paper. pdf

Brown, T. H. (2005). Towards a model for m-learning in Africa. International Journal on ELearning, 4(3), 299-315. Norfolk, VA: AACE. Retrieved January 21, 2014 from http://www.editlib.org/p/5082.

Bureau of Labor Statistics, (2011a). College enrollment and work activity of 2010 high school graduates. Retrieved from: http://www.bls.gov/news.release/hsgec.nr0.htm.

Bureau of Labor Statistics, (2011b). Consumer price index. Retrieved from: http://www.bls.gov.

Bureau of Labor Statistics, (2011c). Labor force statistics from the current population survey. Retrieved from: http://www.bls.gov/cps

Caffarella, R. S., \& Daffron, S. R. (2013). Planning programs for adult learners: A practical guide (3rd ed.). Somerset, N.J: John Wiley \& Sons, 
Cercone, K. (2008). Characteristics of adult learners with implications for online learning design, AACE Journal, 16(2), 137-159.

Christian, A. C. (1982). A comparative study of the andragogical-pedagogical orientation of military and civilian personnel (Doctoral dissertation, Oklahoma State University).

CIA World Factbook. (2011). Ghana. Retrieved from:

https://www.cia.gov/library/publications/the-world-factbook/geos/gh.html\#

Cretchley, G., \& Castle, J. (2001). OBE, RPL and adult education: Good bedfellows in higher education in South Africa. International Journal of Lifelong Education, 20 (6), 487-501.

Cronbach, L. J. (1947). Test “reliability”: Its meaning and determination. Psychometrika, 12(1), $1-16$.

de la Varre, C., Keane, J., \& Irvin, M. J. (2010). Enhancing online distance education in small rural US schools: A hybrid, learner-centered model. ALT-J, Research in Learning Technology, 18(3), 193-205.

Dhlamini, J. P. (2012). Effectiveness of facilitation methods to motivate adult Learners to participate in ABET programs: A case study of the adult center at Ekurhuleni. A doctoral dissertation. Retrieved from: http://uir.unisa.ac.za/bitstream/handle/10500/11819/thesis_dhlamini_jp.pdf?sequence=1

Dray, B., Lowenthal, P., Miszkiewicz, M., Ruiz-Primo, M., \& Marczynski, K. (2011). Developing an instrument to assess student readiness for online learning: A validation study. Distance Education, 32(1), 29-47. Retrieved from http://sehd.ucdenver.edu/update/files/2011/05/DrayLowenthalMisketal2011.pdf

Effah, P., Newman, E., \& Pillay, P. (2009). Tertiary education financing in Ghana. Unpublished mimeo. New York: Partnership for Higher Education in Africa. 
Employment and Training Administration-ETA. (2007). Adult learners in higher education barriers to success and strategies to improve results. Occasional Paper 2007-03. Retrieved from: http://goo.gl/CdLAz

English, L. M., \& Peters, N. (2012). Transformative learning in nonprofit organizations. Adult Education Quarterly, 62 (2), 103-119. doi: 10.1177/0741713610392771

Fidishun, D. (2000, April). Andragogy and technology: Integrating adult learning theory as we teach with technology. Proceedings of the 2000 Mid-South Instructional Technology Conference. Murfreesboro, T.N: Middle Tennessee State University. Retrieved from http://www.mtsu.edu/ itconf/proceed00/fidishun.htm

Flick, U. (2009). An introduction to qualitative research. ( $4^{\text {th }}$ ed.). Thousand Oaks, CA: Sage Publications Limited.

Galusha, J. M. (n.d.) Barriers to learning in distance education. Retrieved from http://www.infrastruction.com/articles.htm

Gay, G. (1994). A synthesis of scholarship in multicultural education. Retrieved from: http://www.ncrel.org/sdrs/areas/issues/educatrs/leaderhsip.leOwin.html Ghana (2003). National medium term private sector development strategy 2004 - 2008. (Vol. 1). Retrieved from http://www.dfid.gov.uk/pubs/files/ghana/priv-sect-dev-strategy-ghana20042008.pd

Hadley, H. N. (1975). Development of an instrument to determine adult educators' orientation: Andragogical or pedagogical. Boston University School of Education.

Hoskins, S. and Hooff, J. (2005) "Motivation and ability: Which students use online learning and what influence does it have on achievement?" British Journal of Educational Technology, 36(2), 177-192. 
Hung, M., Chou, C., Chen, C., \& Own, Z. (2010). Learner readiness for online learning: Scale development and student perceptions. Computers \& Education, 55(3), 1080-1090.

Jacot, A. A., Frenay, M. M., \& Cazan, A. M. (2010). Dropout of adult learners Returning to University: Interactions of Motivational and Environmental factors. Bulletin of the Transilvania University of Brasov. Series VII: Social Sciences. Law, 52, 83-90. Retrieved from EBSCOhost.

Kabuga, C. (1977). Andragogy in developing countries. Half-yearly Journal for Adult Education in Africa, Asia, and Latin America: Why Andragogy. Retrieved from: http://www.umsl.edu/ henschkej/henschke/andragogy_in_developing_countries.pdf

Kasworm, C. (1997). Adult meaning making in the undergraduate classroom. Paper presented at the annual meeting of the American Educational Research Association, Chicago, IL.

Kaymak, Z., \& Horzum, M. (2013). Relationship between online learning readiness and structure and interaction of online learning students. Educational Sciences: Theory and Practice, 13(3), 1792- 1797. doi:10.12738/estp.2013.3.1580

Knowles, M. (1989). The making of an adult educator: A autobiographical journey. San Francisco: Jossey-Bass.

Knowles, M. S., Holton, E. F., \& Swanson, R. A. (2005). The adult learner. (6 ${ }^{\text {th }}$ ed.). Burlington, MA: Elsevier Butterworth-Heinemann.

Krueger, R. A., \& Casey, M. A. (2000). Focus groups: A practical guide for applied research ( $3^{\text {rd }}$ Ed.). Thousand Oaks, Calif.: Sage.

Kwapong, O. A. T. F. (2007a). Assessing willingness to pay for information delivery among rural women in Ghana. International Journal of Emerging Technologies in Learning (iJET), 2, 70-76. 
Kwapong, O. A. T. F. (2007b). Widening access to tertiary education for women in Ghana through distance education. Turkish Online Journal of Distance Education-TOJDE, 8(4), 65 - 79. Retrieved from http://tojde.anadolu.edu.tr/tojde28/articles/article_5.htm

Lin, B., \& Hsieh, C. T. (2001). Web-based teaching and learner control: A research review. Computers \& Education, 37(4), 377-386.

Lumina Foundation (2007). What we know about access, persistence, and success for adult learners in postsecondary education: A review of contemporary literature. Retrieved from http://www.luminafoundation.org/research/what_we_know/adult_learners/

Mattice, N. J., \& Dixon, P. S. (1999). Student preparedness for distance education. Santa Clarita, CA: College of the Canyons. (ERIC Document Reproduction Service No. ED436216)

Mangesi, K. (2007). ICT in Education in Ghana. Survey of ICT and Education in Africa: Ghana Country Report. Retrieved from: www.infodev.org

Mbilinyi, L. (2006). Degrees of opportunity: adults' views on the value and feasibility of returning to school. Informally published manuscript, TNS Research, Capella University, Minneapolis, MN. Retrieved from: http://www.degreesofopportunity.org/inc/degrees_opportunity_report.pdf

Merriam, S. B., \& Caffarella, R. S. (1999). Learning in adulthood. (2 ${ }^{\text {nd }}$ Ed.). San Francisco: Jossey-Bass.

Mezirow, J. (1978). Perspective transformation. Adult Education, 28, 100-110.

Mezirow, J. (1978). Education for perspective transformation. Women's re-entry programs in community colleges. New York: Teachers College, Columbia University.

Mezirow, J., Taylor, E. W., \& Associates. (2009). Transformative learning in practice: Insights from community, workplace, and higher education. San Francisco: Jossey-Bass. 
McVay, M. (2000). Developing a web-based distance student orientation to enhance student success in an online bachelor's degree completion program. Unpublished practicum report presented to the Ed.D. Program. Florida: Nova Southeastern University.

McVay, M. (2001). How to be a successful distance learning student: Learning on the Internet. New York: Prentice Hall.

Min-Ling H., Chien C., Chao-Hsiu C., \& Zang-Yuan O. (2010). Learner readiness for online learning: Scale development and student perceptions. Computers \& Education 55(3), 1080-1090. Retrieved from http://www.sciencedirect.com/science/article/pii/S0360131510001260

Newman, M. (2012). Calling transformative learning into question: Some mutinous thoughts. Adult Education Quarterly, 62(1), 36-55. doi: 10.1177/ 0741713610392768

Otter, R. R., Seipel, S., Graeff, T., Alexander, B., Boraiko, C., Gray, J., ... \& Sadler, K. (2013). Comparing student and faculty perceptions of online and traditional courses. The Internet and Higher Education, 19, 27-35.

Rauber, D. F. (1969). Macbeth, Macbeth, Macbeth. Criticism, 59-67.

Rule, P. \& Modipa, T, R (2012). We must believe in ourselves: Attitudes and experiences of adult learners with disabilities in KwaZulu-Natal, South Africa”. Adult Education Quarterly, 62(2), 138-158.

Sealey-Ruiz, Y. (2007). Wrapping the curriculum around their lives: Using a culturally relevant curriculum with African American adult women. Adult Education Quarterly, 58(1), 4460.

Smith, P. J., Murphy, K. L., \& Mahoney, S. E. (2003). Towards identifying factors underlying readiness for online learning: An exploratory study. Distance Education, 24(1), 57-67. 
Retrieved from

http://www.tandfonline.com/doi/abs/10.1080/01587910303043\#.VBsGM5RdWSo

Tannehill, D. B. (2009). Andragogy: How Do Post-Secondary Institutions Educate and Service Adult Learners? (A doctoral dissertation). Retrieved from: http://dscholarship.pitt.edu/7872/1/TannehillDissertationFinal.pdf

Tetteh-Richter, D. (2014). Integrating online learning into University Education in Ghana: The prospects and challenges for working-class adult learners in the urban areas, a midatlantic case study (Unpublished doctoral comprehensive exam). West Virginia University, Morgantown, WV.

United States National Center for Education Statistics (2011). Digest of education statistics. National Center for Education Statistics. Retrieved from: http://nces.ed.gov/programs/digest/d11/ch_3.asp

Watkins, R., Leigh, D., \& Triner, D. (2004). Assessing readiness for e-learning. Performance Improvement Quarterly, 17(4), 66-79. Retrieved from: http://www.readcube.com/articles/10.1111\%2Fj.19378327.2004.tb00321.x?r3_referer=wol\&show_checkout=1

Zamanou, S. (1993). Differences do make a difference: Recruitment strategies for the nontraditional student. Paper presented at the annual meeting of the Speech Communication Association, Miami, FL. (ERIC Document Reproduction Service No. ED 367 034) 


\section{Appendix A}

\section{ADULT LEARNERS READINESS FOR ONLINE LEARNING IN GHANA - Survey Questions}

Hello, as part of my dissertation process, I have to collect data to help me determine whether online learning can be successfully implemented in university education in Ghana among adult learners. You are therefore invited to participate in this survey. Your participation in this study is completely voluntary. There are no foreseeable risks associated with this project. However, if you feel uncomfortable answering any question, kindly skip that question. It is important that you share your honest opinions. Your survey responses will be kept strictly confidential.

* Please, enter your email address at the end of the survey if you wish to take part in a raffle drawing for a chance to win one (1) of ten (10) phone card units worth 50 GHC

* Thank you very much for taking the time to participate in this study.

\section{Q1 Please identify your gender.}

O Male

Female

\section{Q2 Kindly identify your age group}

21 yrs - 30 yrs

O 31 yrs - 40 yrs

41 yrs -50 yrs

O 51 yrs and above 
Q3 Are you currently enrolled in a university degree program?

O Yes

No

Q4 Are you currently employed?

O Yes

O No

Q5 What is your marital status?

Single

O Married

Divorced

Q6 Do you have any children?

Y Yes

O No

Q7 What is your educational background?

Undergraduate

O Master's

O $\mathrm{PhD} /$ doctoral

Some other certificate 
Q10. Below are lists of statements expressing opinions about your skill level with computers and the Internet.

For each statement please choose the option that indicates your position best - how much you agree or disagree with that statement.

The five positions from which to choose are:

5- I strongly agree with this statement.

4- I agree with this statement

3 - I'm not certain about this statement to agree or disagree.

2 - I disagree with this statement.

1 - I strongly disagree with this statement 


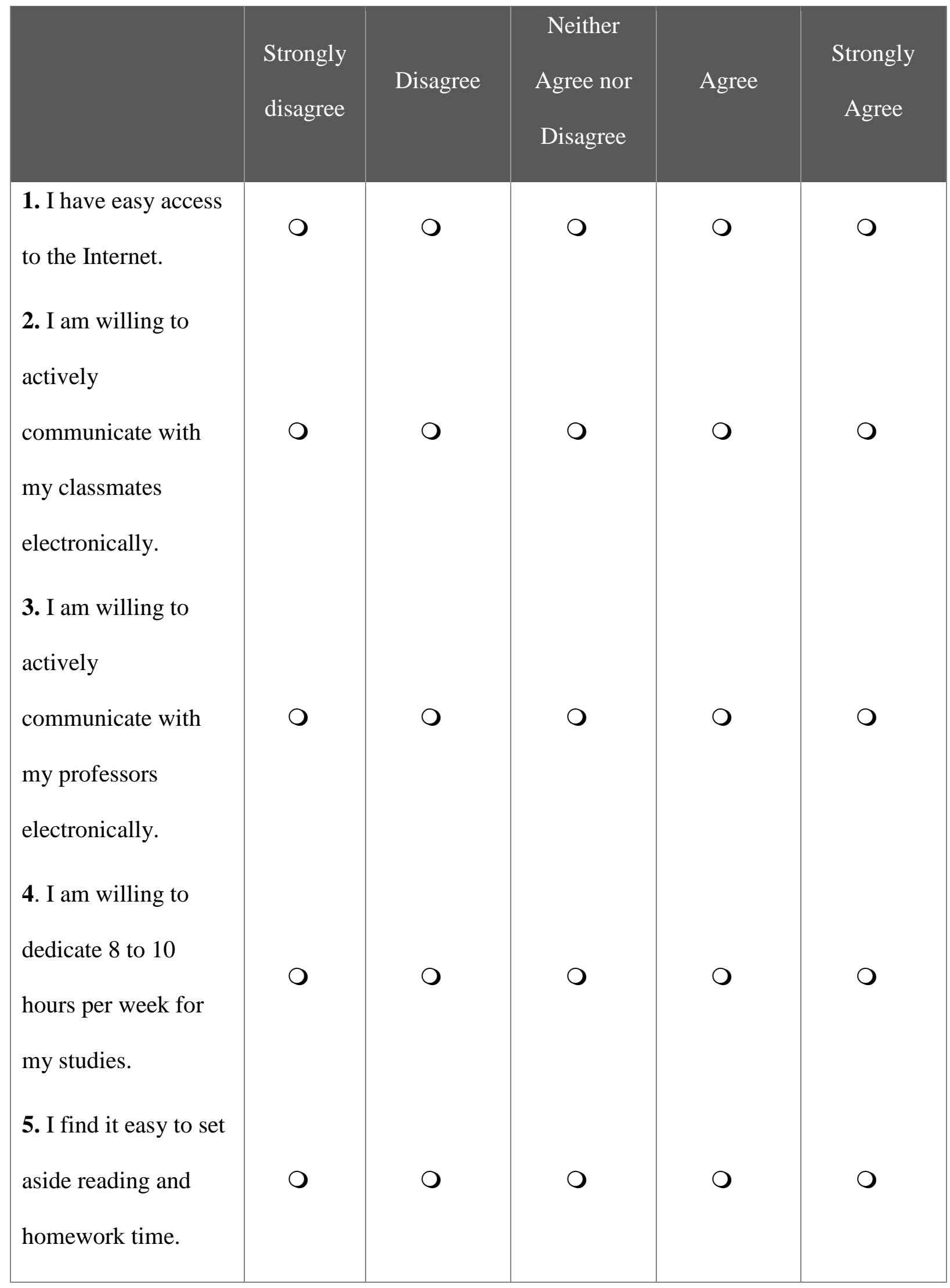




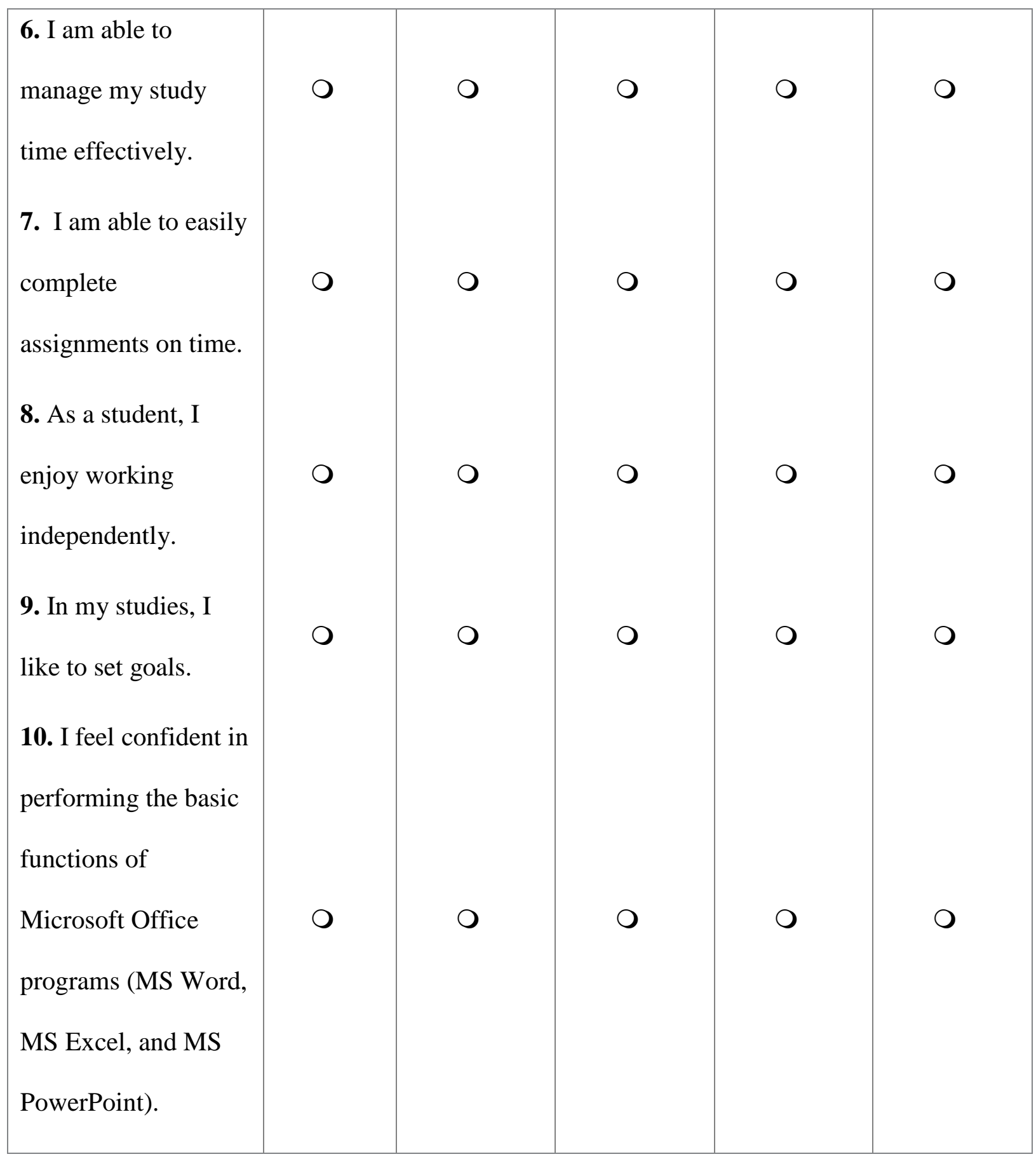




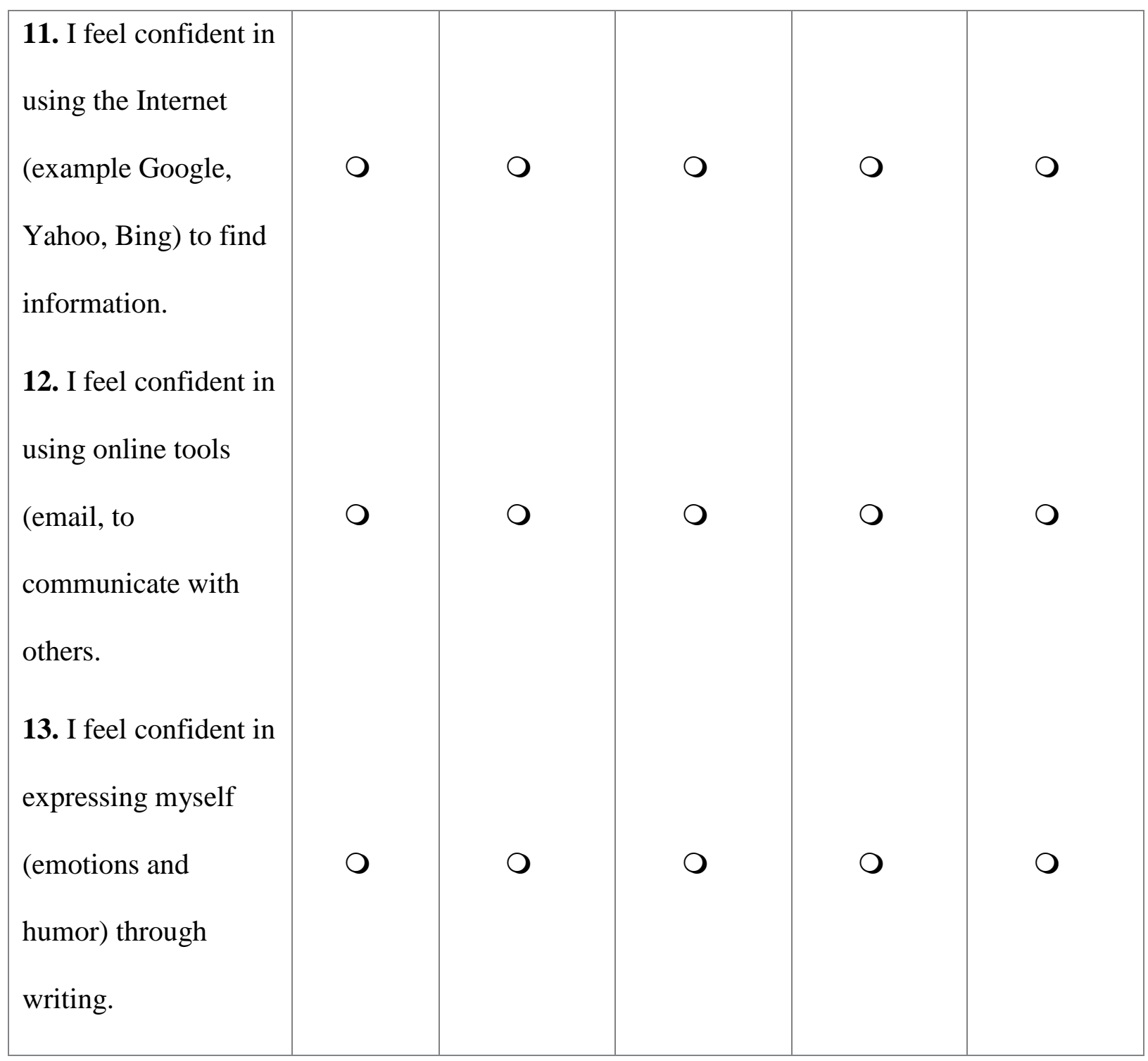


Q11. Below are a list of statements expressing opinions about the manner in which faculty members teach in the Ghanaian universities.

For each statement please choose the option that indicates your position best - how much you agree or disagree with that statement.

The five positions from which to choose are:

5 - I strongly agree with this statement.

4 - I agree with this statement

3 - I'm not certain about this statement to agree or disagree.

2 - I disagree with this statement.

1 - I strongly disagree with this statement 


\begin{tabular}{|c|c|c|c|c|c|}
\hline & $\begin{array}{l}\text { Strongly } \\
\text { Disagree }\end{array}$ & Disagree & $\begin{array}{c}\text { Neither } \\
\text { Agree nor } \\
\text { Disagree }\end{array}$ & Agree & $\begin{array}{c}\text { Strongly } \\
\text { Agree }\end{array}$ \\
\hline $\begin{array}{l}\text { 1. The instructor } \\
\text { presents } \\
\text { information as the } \\
\text { absolute truth. } \\
\text { 2. The instructor } \\
\text { encourages me to } \\
\text { examine my } \\
\text { feelings, attitudes } \\
\text { and behaviors. } \\
\text { 3. The instructor } \\
\text { allows me to } \\
\text { actively participate } \\
\text { in deciding what is } \\
\text { to be learned and } \\
\text { how it is to be done. }\end{array}$ & . & 0 & . & 更 & 更 \\
\hline
\end{tabular}




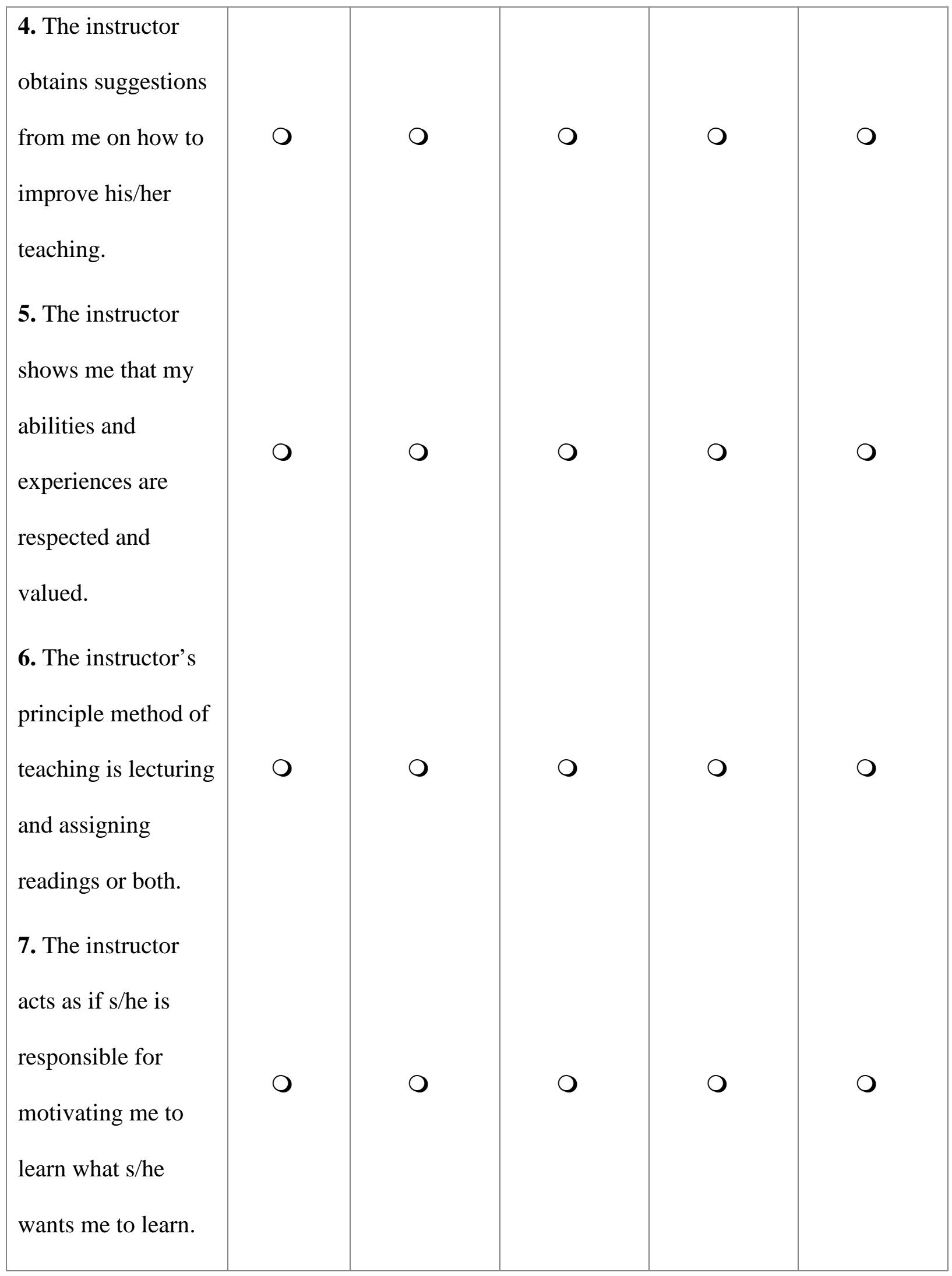




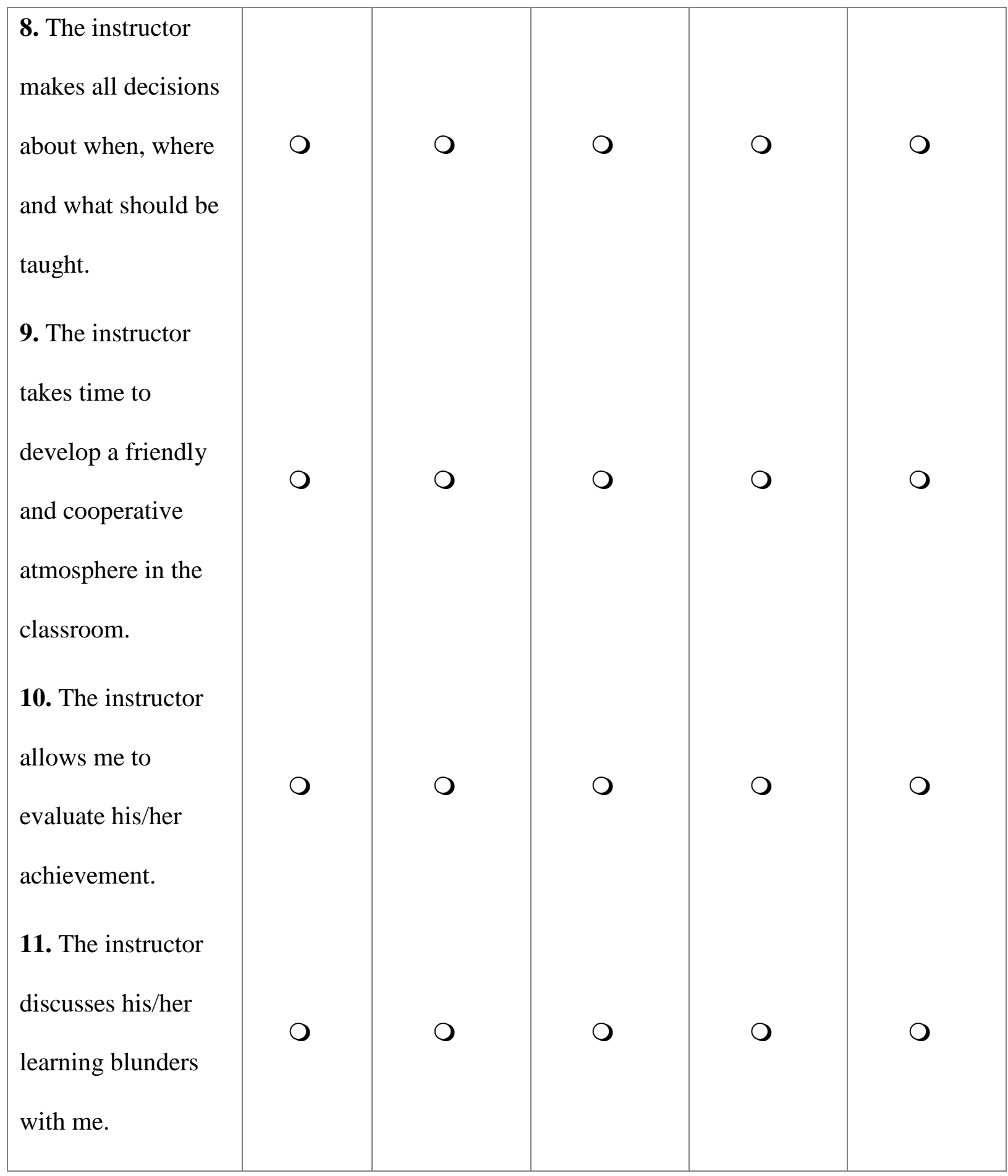




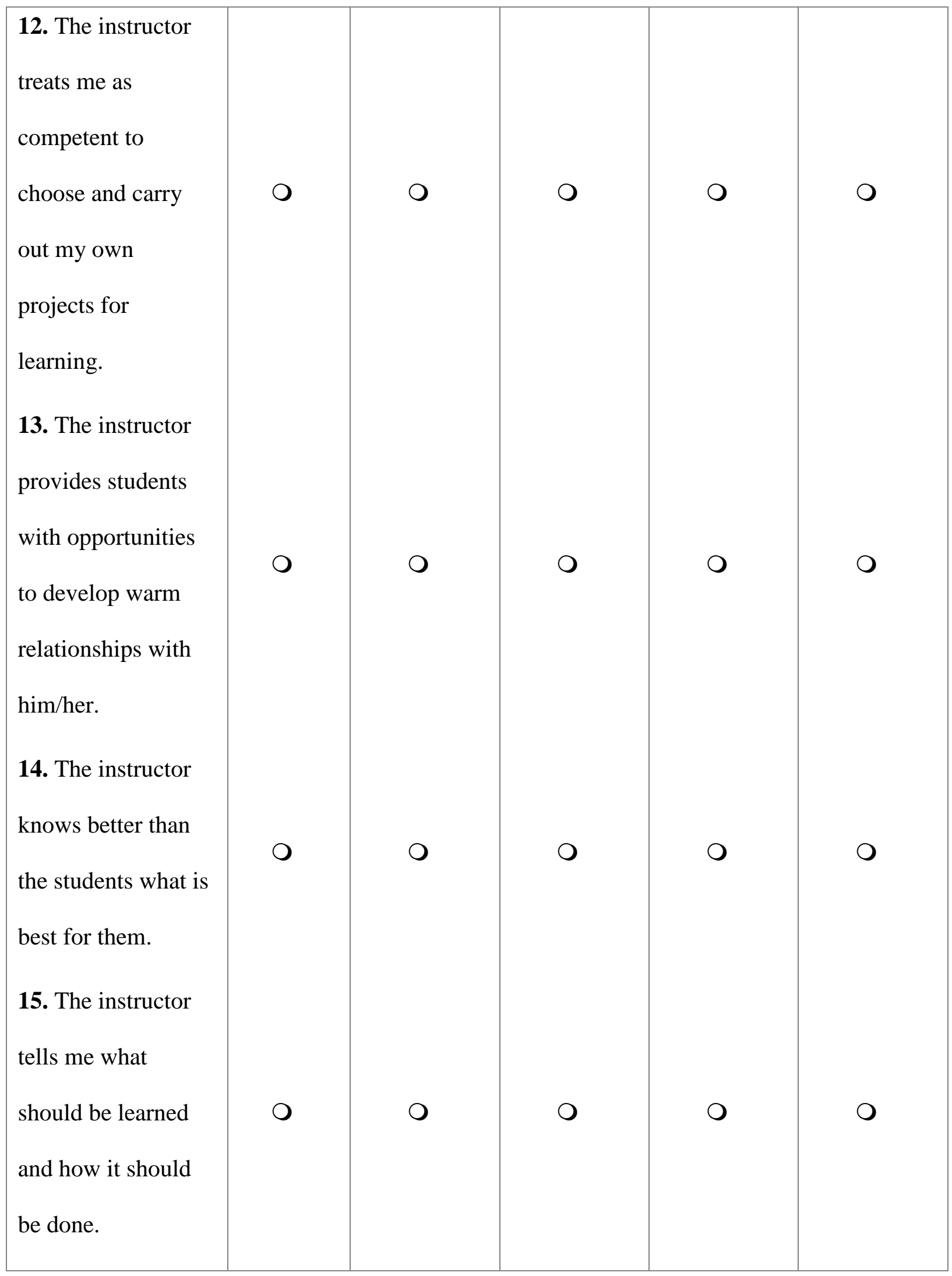




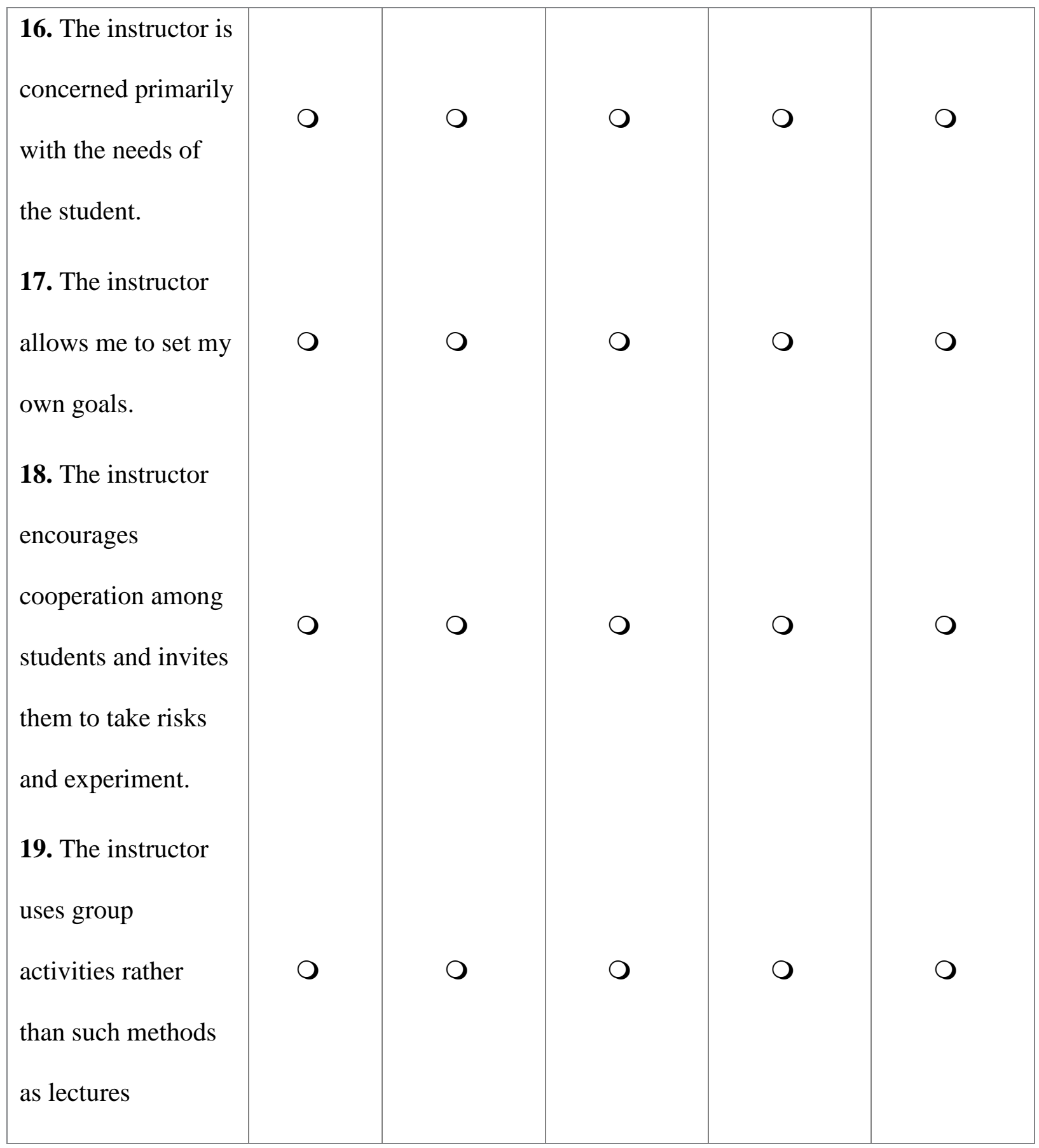

Q12. Below are lists of statements expressing opinions on how online learning is perceived as compared to traditional learning in Ghanaian universities. For each statement please choose the 
option that indicates your position best - how much you agree or disagree with that statement. The five positions from which to choose are:

5 - I strongly agree with this statement.

4 - I agree with this statement

3 - I'm not certain about this statement to agree or disagree.

2 - I disagree with this statement.

1 - I strongly disagree with this statement 


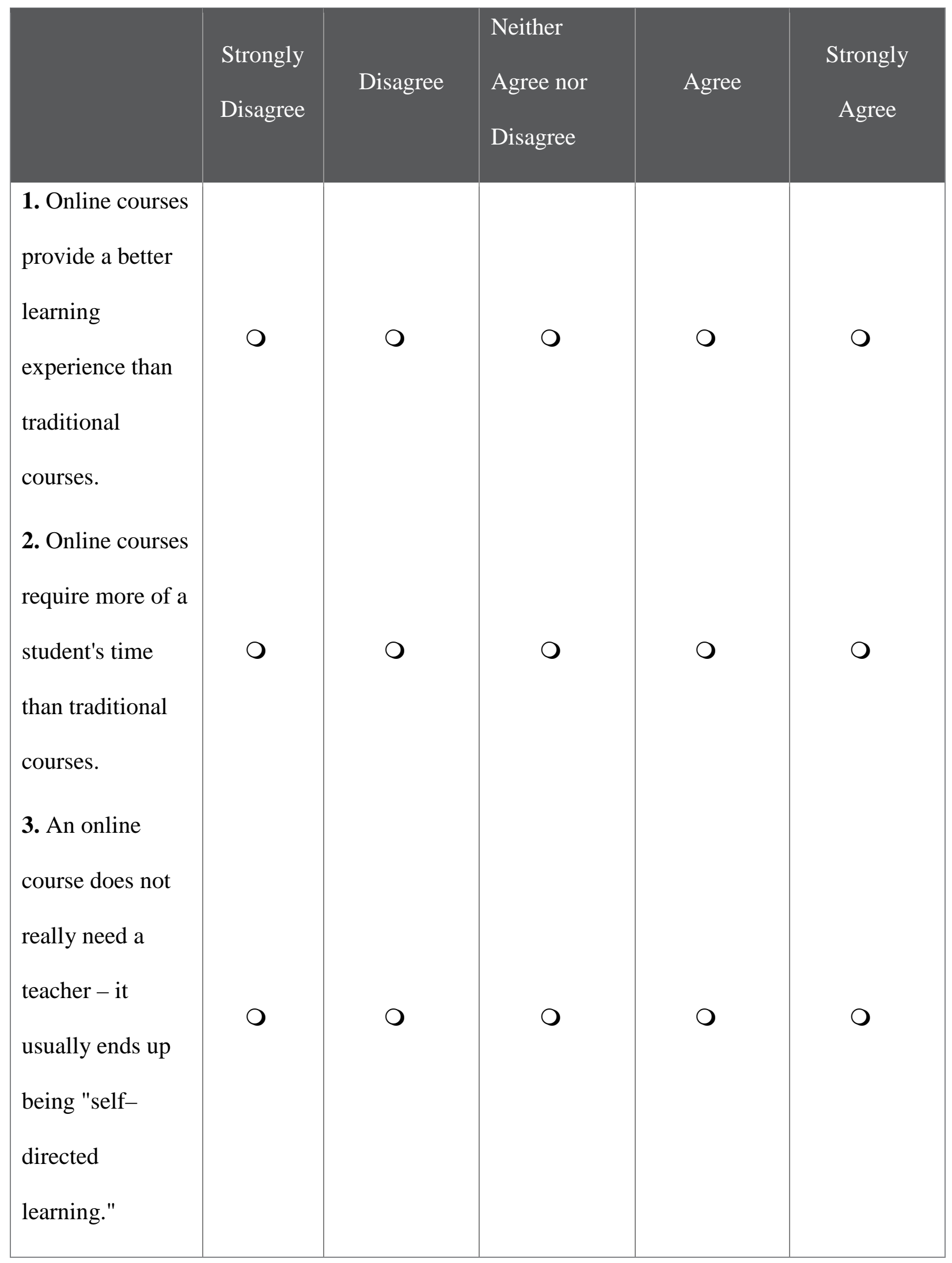




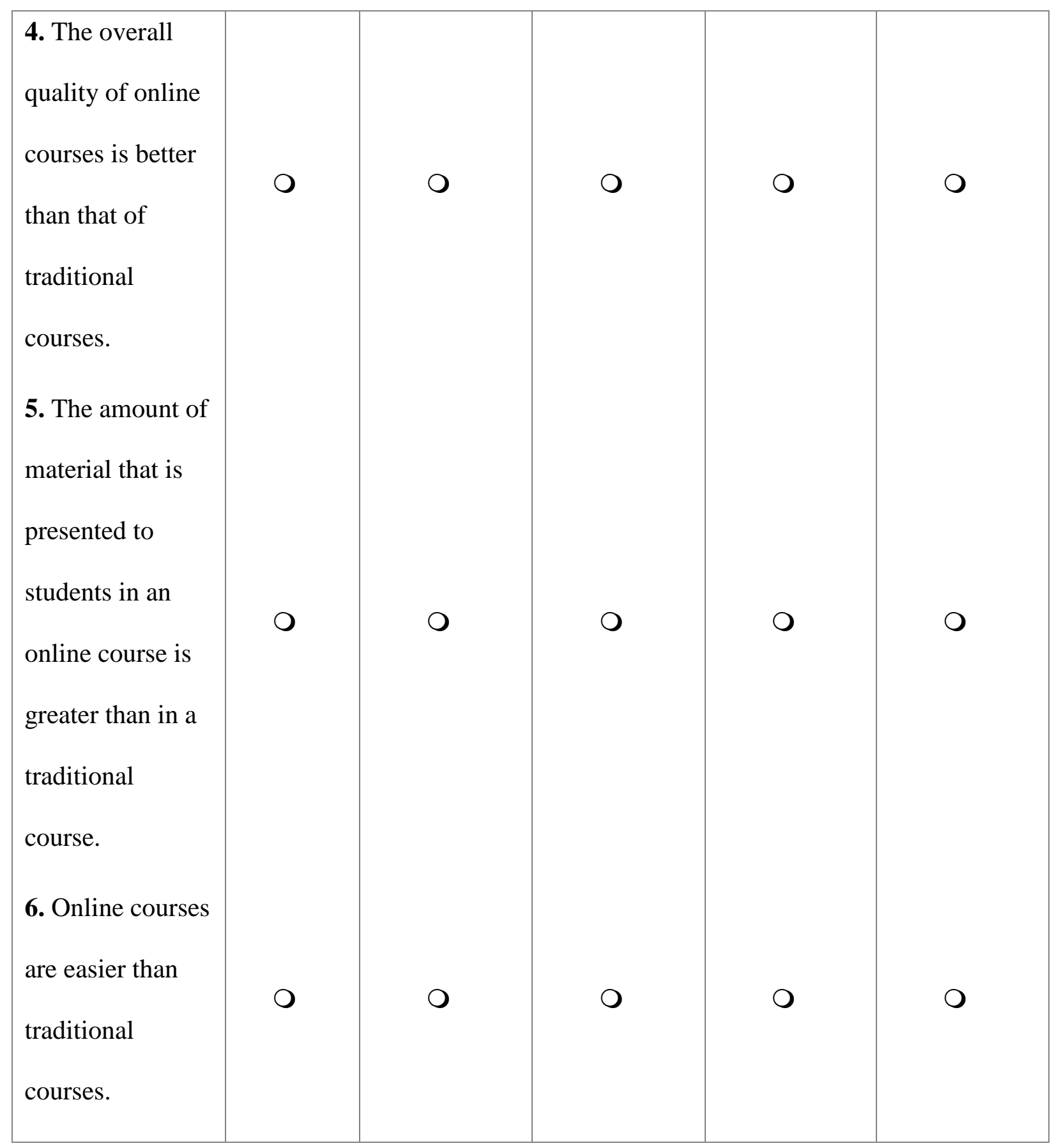




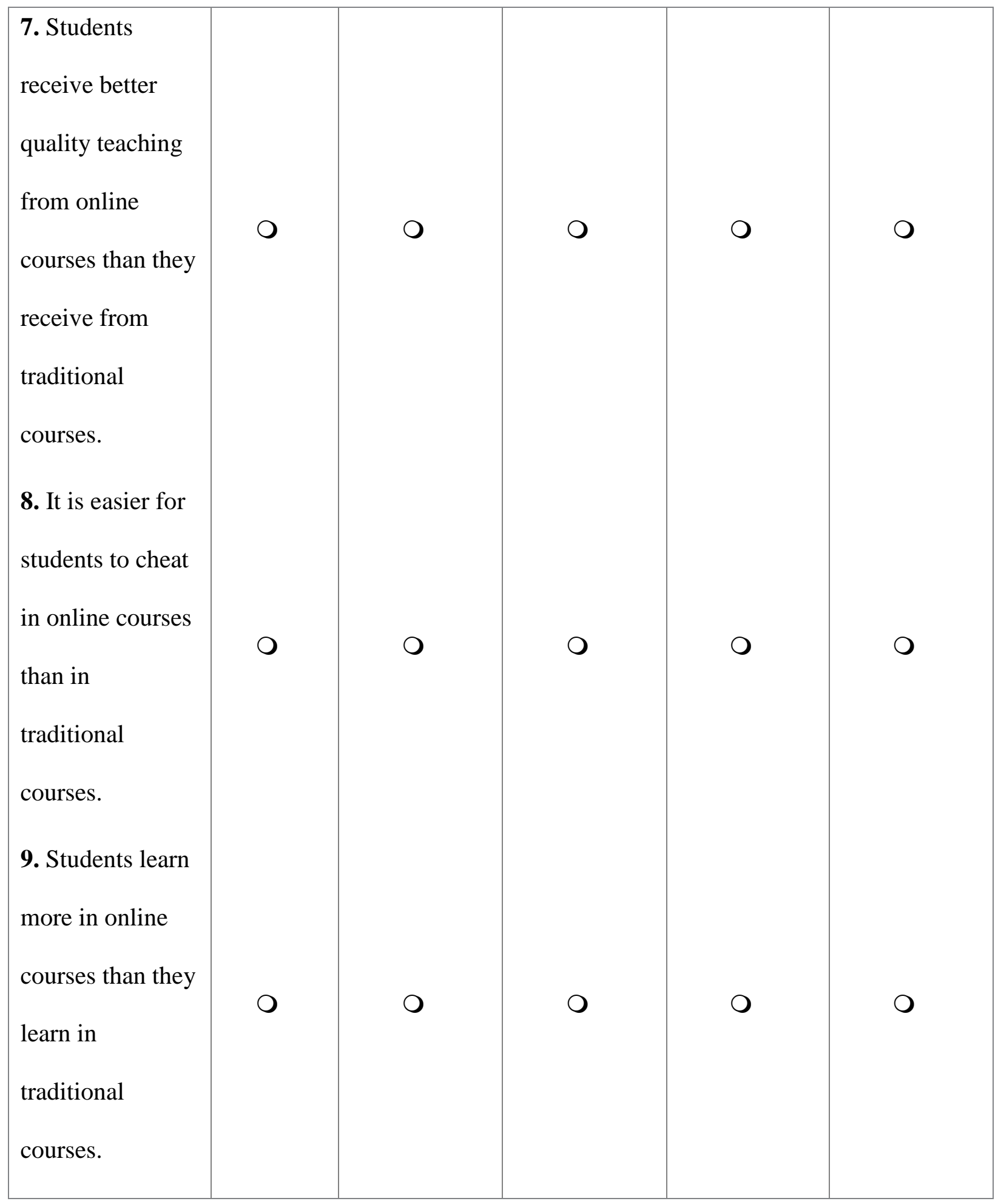


Q15 Will you like to enter into the raffle draw? Enter your email after submitting the survey.

Yes

No

If Yes Is Selected, Then Skip To Click to write the question text 
Q17 Please, enter your email address to take part in the raffle drawing for a chance to win one (1) of ten (10) phone card units worth 50 GHC.

This is the end of the survey. Please share the survey link with your colleagues. Remember to copy your "Response ID”. It is the code for the raffle.

You now have the option of providing your Response ID to be entered in a raffle for a 50 GHC worth of phone units. Since your Response ID is provided on a separate survey, it will not be connected to your specific responses in the previous survey. Therefore, your responses on the previous survey will remain anonymous. 